\title{
Structure development in amorphous AlCeNi alloys
}

\author{
U Schmidt ${ }^{1,3}$, Ch Eisenschmidt ${ }^{1}$, F Syrowatka $^{1}$ and N Menguy ${ }^{2}$ \\ ${ }^{1}$ Martin-Luther-University, Department of Physics, Hoher Weg 8, Halle, Germany \\ ${ }^{2}$ Laboratoire de Mineralogie-Cristallographie de Paris, UMR 7590, Universites Paris 6 et 7 , \\ IPGP Case 115, 4 Place Jussieu 75252 Paris cedex 05, France \\ E-mail: schmidt@physik.uni-halle.de
}

Received 7 February 2005, in final form 19 July 2005

Published 5 August 2005

Online at stacks.iop.org/JPhysCM/17/5111

\begin{abstract}
The forming and decomposition of $\mathrm{Al}_{84} \mathrm{Ce}_{6} \mathrm{Ni}_{10}$ and $\mathrm{Al}_{81} \mathrm{Ce}_{10} \mathrm{Ni}_{9}$ glasses produced by melt spinning under different melt temperatures and cooling rates was investigated by means of x-ray diffraction (XRD), electron microscopy (TEM and ESEM), electrical resistivity (ER) and calorimetric measurements during isothermal and continuous heating. The influence of the different production conditions on the relaxation, glass transition and crystallization are analysed. In the $\mathrm{Al}_{84} \mathrm{Ce}_{6} \mathrm{Ni}_{10}$ glasses the melt temperature and cooling rate do not have a strong influence on the glass forming, the transition to the supercooled liquid (SL) and the formation of a eutectic as the first crystalline structure. In the $\mathrm{Al}_{81} \mathrm{Ce}_{10} \mathrm{Ni}_{9}$ materials the different synthesis conditions produce fully or partial amorphous structure in the as-quenched state. The transformation to the crystalline structure without glass transition occurs with the formation of $\mathrm{NC}-\mathrm{fcc} \mathrm{Al}$ (nanocrystals) before a eutectic crystallization is dominant.
\end{abstract}

\section{Introduction}

According to Inoue and co-workers [1-5], Al-based amorphous alloys with low $\mathrm{Ni}$ and $\mathrm{Ce}$ contents prepared by melt spinning show interesting properties such as high specific strength, ductility and corrosion resistance. While the authors in [1] mention the production and the limits of AlCe alloys, the existence of a glass transitions in $\mathrm{Al}-\mathrm{Ce}-\mathrm{Ni}$ is first described in [2]. In [3, 4] a nucleation growth process of nanocrystalline grains in an amorphous $\mathrm{Al}_{87} \mathrm{Ni}_{10} \mathrm{Ce}_{3}$ is described with the assumption of pre-existing nuclei. In Inoue's paper [5] the important findings with respect to $\mathrm{Al}-\mathrm{Ce}-\mathrm{Ni}$ amorphous alloys are reviewed until 1995. The crystallization behaviour of $\mathrm{Al}_{90-x} \mathrm{Ni}_{10} \mathrm{Ce}_{x}$ alloys was found to be dependent on the $\mathrm{Ce}$ concentration [6]. If the alloys contain $\leqslant 4$ at. $\% \mathrm{Ce}$, primary crystallization of nanoscale $\alpha$ (fcc) Al particles is reported to occur before the precipitation of two intermetallic compounds $\left(\mathrm{Al}_{3} \mathrm{Ni}\right.$ and $\left.\mathrm{Al}_{11} \mathrm{Ce}_{3}\right)$ from the residual amorphous matrix. At 5 at.\% Ce, a glass transition

3 Author to whom any correspondence should be addressed. 
occurs before simultaneous precipitation of $\alpha$ (fcc)Al and an unidentified phase followed by the precipitation of $\mathrm{Al}_{3} \mathrm{Ni}$, whereas at 10 at. $\% \mathrm{Ce}$ a one-step crystallization process is observed and a glass transition is mentioned only in an earlier work [1]. The formation of nanoscale $\alpha$ (fcc) $\mathrm{Al}$ in an $\mathrm{Al}_{87} \mathrm{Ni}_{10} \mathrm{Ce}_{3}$ alloy is related to the presence of strong local concentration fluctuations in the as-quenched state. Regions without Ce may act as pre-existing nuclei and induce precipitation of $\alpha-\mathrm{Al}$; regions with higher $\mathrm{Ce}$ and $\mathrm{Ni}$ contents directly transform into compounds at higher temperatures.

In their work Munoz-Morris et al [7] restrict the formation of the amorphous structure during the rapid quenching for an $\mathrm{Al}-\mathrm{Ce}-\mathrm{Ni}$-alloy at Ce concentration between 0 and 6 at.\% and $\mathrm{Ni}$ between 4 and 10 at.\%. Not all materials are fully amorphous. Only $\mathrm{Al}_{90} \mathrm{Ni}_{4} \mathrm{Ce}_{6}$ and $\mathrm{Al}_{88} \mathrm{Ni}_{8} \mathrm{Ce}_{4}$ are fully amorphous and form NC (nanocrystals) of $\alpha$-fcc-Al. Using DSC three exothermic peaks are measured during the constant heating.

According to Fang $[8,9]$ the crystallization in an amorphous alloy $\mathrm{Al}_{90} \mathrm{Ni}_{5} \mathrm{Ce}_{5}$ begins with the formation of $\mathrm{NC}$ of $\alpha$-fcc- $\mathrm{Al}$ in the amorphous matrix at low temperatures around $150{ }^{\circ} \mathrm{C}$ without the transition to the supercooled liquid (SL). According to the authors the pre-peak in the XRD patterns, which is located at $2 \theta=19.5^{\circ}$ [9], can be correlated to structural complexes evoked by chemical short and medium range order. This means that a strong chemical bond exists in the amorphous alloys as well [10].

One of the most important parameters of the production is the quenching rate and the melt temperature, which can modify the viscosity of the melt. The formation of the metallic glasses is strongly dependent on the processing parameters as Fang et al [11] have explained for $\mathrm{Al}_{90} \mathrm{Ni}_{5} \mathrm{Ce}_{5}$ ribbons. In [12] the influence of the initial temperature on the structure and properties of an amorphous $\mathrm{Al}_{91} \mathrm{Ce}_{5} \mathrm{Ni}_{4}$ alloy is discussed.

The activation energy of $\mathrm{Al}_{85} \mathrm{Ce}_{5} \mathrm{Ni}_{10}$ is determined only by Cochrane et al [13] using the Kissinger method of the DSC curve and the Arrhenius plot from the isothermal ageing of the first transformation peak. They calculate rather large values for the activation energy of about $500 \mathrm{~kJ} \mathrm{~mol}^{-1}$. They also give information about the kinetic parameter but there is no evidence of the existence of the SL. However the authors remark that the experimental curves are not suitable for a linear fitting in the JMA plots.

No explanation is given for the changes of the decomposition for an increase of the $\mathrm{Ce}$ ( $>6$ at \%) and $\mathrm{Ni}(>6$ at \%) concentration in Al-Ce-Ni materials. Of interest is the existence of two peaks during the transformation of the amorphous state to the first crystalline structure without a visible region of SL but formation of NC.

The authors in [9] remark that the structure corresponding to the pre-peak is not stable during the crystallization process in amorphous $\mathrm{Al}-\mathrm{Ce}-\mathrm{Ni}$ alloys. The larger Ce concentration stabilized the amorphous state with respect to the precipitation of the Al nano-particles in the residual amorphous matrix. This causes a decrease of the diffusivity of the Al. Another trend is the increase of the crystallization onset temperature.

The authors in [6] have investigated the structure development of alloys with a large Ni content (10 at.\%) for three $\mathrm{Al}_{(90-x)} \mathrm{Ce}_{x} \mathrm{Ni}_{10}$ alloys $(x=3,5,10$ at.\%). They conclude that in $\mathrm{Al}_{87} \mathrm{Ce}_{3} \mathrm{Ni}_{10}$ fluctuation in the concentration is the cause for the crystallization. The concentration fluctuation is presumed to be associated with pre-existing nuclei. However, in $\mathrm{Al}_{85} \mathrm{Ce}_{5} \mathrm{Ni}_{10}$ and $\mathrm{Al}_{80} \mathrm{Ce}_{10} \mathrm{Ni}_{10}$ crystallization is a nucleation and growth process, because the formation of nuclei can take place when the concentration is close to the concentration of the equilibrium.

The present work intends to verify some of these findings, for two different $\mathrm{Al}-\mathrm{Ce}-\mathrm{Ni}$ materials produced by melt spinning of an $\mathrm{Al}_{84} \mathrm{Ce}_{6} \mathrm{~N}_{10}$ and an $\mathrm{Al}_{81} \mathrm{Ce}_{10} \mathrm{Ni}_{9}$ alloy. Various experimental techniques are applied to study the evolution of the structure in the as-quenched state and the continuous heating by DSC and in situ electrical resistivity measurements - the 
latter one is performed for the first time on these particular alloys. Their high sensitivity allows us to unambiguously detect relaxation phenomena that occur prior to glass transition and/or crystallization.

We will use XRD and TEM analysis to investigate the structure development from the amorphous to the crystalline state. Calorimetric and electrical resistance measurements during the isothermal heating will complete the investigation and help us to understand the kinetics of the transformation and decomposition process in the different steps. Additionally, we will investigate whether an influence of the melting temperature and cooling rate on the structure development of the $\mathrm{Al}_{84} \mathrm{Ce}_{6} \mathrm{~N}_{10}$ and $\mathrm{Al}_{81} \mathrm{Ce}_{10} \mathrm{Ni}_{9}$ ribbons exists.

\section{Experimental details}

The alloys of $\mathrm{Al}_{84} \mathrm{Ce}_{6} \mathrm{Ni}_{10}$ and $\mathrm{Al}_{81} \mathrm{Ce}_{10} \mathrm{Ni}_{9}$ are prepared from the materials $6 \mathrm{~N} \mathrm{Al}$ and lumps of $3 \mathrm{~N}$ Ce and $3 \mathrm{~N}$ Ni by induction melting under argon atmosphere. Ribbons are prepared from the ingots using a single-roller-melt-spinning plant at different copper wheel speeds and different melting temperatures [14]. The first wheel speed $\left(44 \mathrm{~m} \mathrm{~s}^{-1}\right)$ of this plant corresponds to a cooling rate on the substrate side of $\dot{T}_{\mathrm{C} 1}=5 \times 10^{5} \mathrm{~K} \mathrm{~s}^{-1}$ and in a second series the wheel speed was $30 \mathrm{~m} \mathrm{~s}^{-1}$, corresponding to a cooling rate of $\dot{T}_{\mathrm{C} 2}=10^{5} \mathrm{~K} \mathrm{~s}^{-1}$. The relation between the wheel speed and cooling rate was validated using two different methods, described in more details in [15], by the measurement of the thickness of the ribbons at different Al materials and in addition the modelling of the dendritic growth of $\mathrm{AlCu}$ alloys. The melt temperatures $\left(T_{\mathrm{m} 1}-T_{\mathrm{m} 4}\right)$ are varied between $T_{\mathrm{m} 1}=1100^{\circ} \mathrm{C}$ and $T_{\mathrm{m} 4}=1400^{\circ} \mathrm{C}$ in $100^{\circ} \mathrm{C}$ steps.

The structure and its development are examined by TEM using a JEOL $2010 \mathrm{~F}$ microscope and a scanning transmission electron microscope (Philips ESEM XL 30 FEG with EDX). Using energy dispersive $\mathrm{x}$-ray spectroscopy (EDX) we are able to determine the element distribution after different ageing regimes. The development of the diffraction pattern (lattice parameter and crystalline structure) was studied with an X-ray diffractometer (D5000, $\mathrm{Cu} \mathrm{K} \alpha$ radiation) and a Philips MPD theta-theta powder diffractometer, $\mathrm{Cu} \mathrm{K} \alpha$ radiation too, both in the $2 \Theta$ interval between $10^{\circ}$ and $70^{\circ}$.

Information on the transformation kinetics was obtained from calorimetric measurements with a Perkin-Elmer DSC apparatus and from electrical resistance measurement at a constant current of $I=0.2$ A with a four-point device including a digital voltmeter and interface coupling to a computer. For a more detailed description of all experimental methods used, see [14].

\section{Experimental results}

\subsection{The as-quenched state}

All $\mathrm{Al}_{84} \mathrm{Ce}_{6} \mathrm{Ni}_{10}$ ribbons, between a melt temperature of $1100{ }^{\circ} \mathrm{C}$ and $1400{ }^{\circ} \mathrm{C}$ and cooling rates of $\dot{T}_{\mathrm{C} 1}$ and $\dot{T}_{\mathrm{C} 2}$, are amorphous. The XRD spectra of five of these eight ribbons are shown in figure $1(\mathrm{a})$, inset. The $\mathrm{Al}_{81} \mathrm{Ce}_{10} \mathrm{Ni}_{9}$ ribbons are amorphous for the cooling rate $\dot{T}_{\mathrm{C} 1}$ but in the case of the cooling rate $\dot{T}_{\mathrm{C} 2}$ the material melting $\leqslant 1200^{\circ} \mathrm{C}$ shows crystalline parts in the as-quenched state; see figure 1(b), inset. The peaks can be correlated with an orthorhombic structure of $\mathrm{Al}_{4} \mathrm{Ce}$ [16].

The calculation of the structure factor $(S(Q))$ after Faber and Ziman [17] shows for the complete amorphous alloys $\mathrm{Al}_{84} \mathrm{Ce}_{6} \mathrm{Ni}_{10}$ a main peak at about $Q=26 \mathrm{~nm}^{-1}$ and a weak but wide pre-peak (figure 1(a)). For the different cooling rates the main peak is shifted between 25.9 and $25.4 \mathrm{~nm}^{-1}$. In the full amorphous $\mathrm{Al}_{81} \mathrm{Ce}_{10} \mathrm{Ni}_{9}$ materials (figure 1(b)) the main peak 
(a)

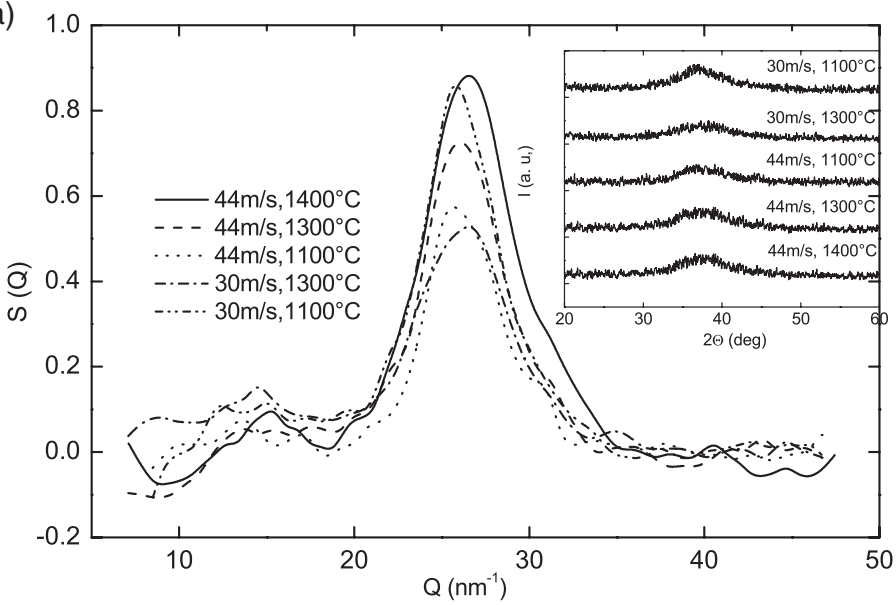

(b)

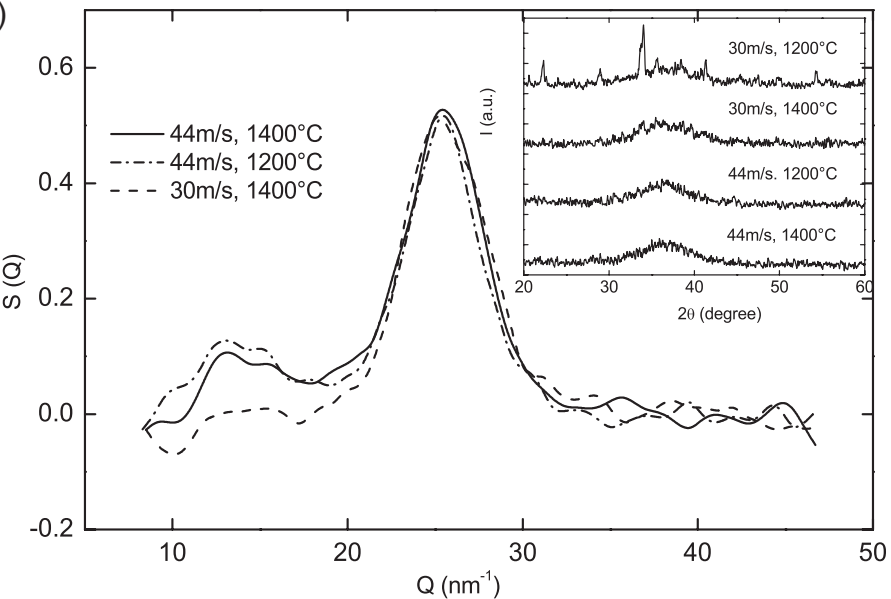

(c)

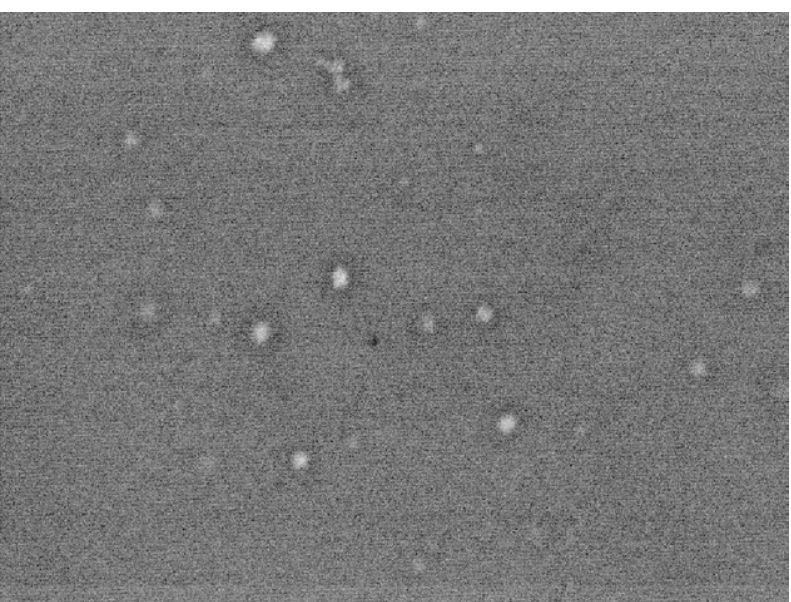

Figure 1. (a) The $S(Q)$ development of $\mathrm{Al}_{84} \mathrm{Ce}_{6} \mathrm{Ni}_{10}$ of the as-quenched state of different production conditions; inset, the XRD curves belonging to it. (b) The $S(Q)$ development of $\mathrm{Al}_{81} \mathrm{Ce}_{10} \mathrm{Ni}_{9}$ of the as-quenched state of different production conditions; inset, the XRD curves belonging to it. (c) The BSE pictures of $\mathrm{Al}_{81} \mathrm{Ce}_{10} \mathrm{Ni}_{9}$ in the as-quenched state. (d) The diffraction picture (TEM images) of the as-quenched state of $\mathrm{Al}_{81} \mathrm{Ce}_{10} \mathrm{Ni}_{9}$. (e) The BSE pictures of $\mathrm{Al}_{84} \mathrm{Ce}_{6} \mathrm{Ni}_{10}$ in the as-quenched state. 
(d)

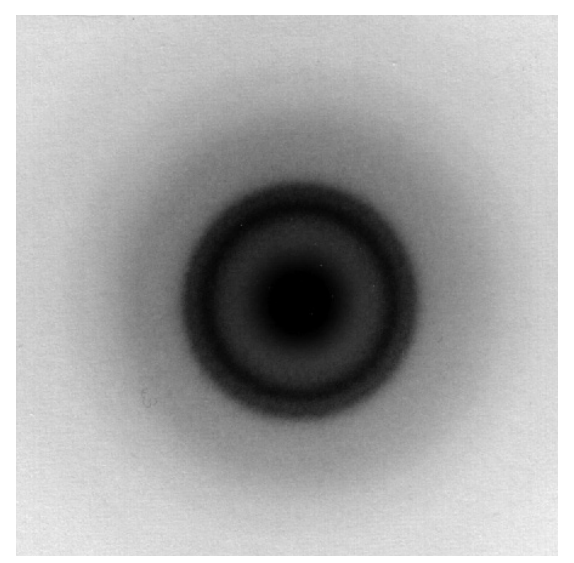

(e)

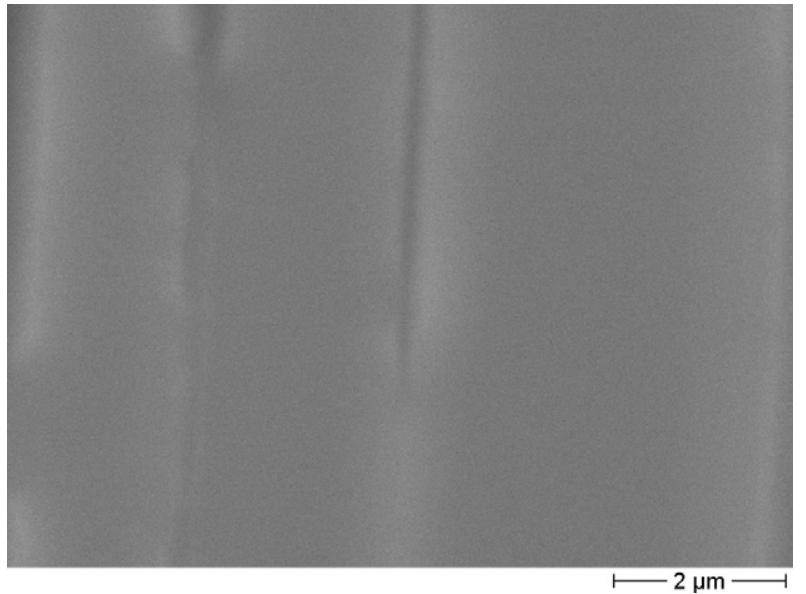

Figure 1. (Continued.)

is located at $25.5 \mathrm{~nm}^{-1}$ with small variations depending on the different production conditions. The pre-peak at $13.1 \mathrm{~nm}^{-1}$ is more intensive for the ribbons produced at the cooling rate $\dot{T}_{\mathrm{C} 1}$. It appears as a double peak with a maximum at $13.2 \mathrm{~nm}^{-1}$ and at $15.3 \mathrm{~nm}^{-1}$. The $Q$-value for the main peak conforms to the nearest distance of the $\mathrm{Al}$-atoms with small influence of the $\mathrm{Ce}$ or Ni atoms.

The prepeak is a hint at the incomplete mixing during the melting, as it is very improbable that the agglomeration takes place during the cooling. This is the small diffusion ability of the $\mathrm{Ce}$ and $\mathrm{Ni}$ atoms. In the $\mathrm{BSE}$ picture of the ESEM of $\mathrm{Al}_{81} \mathrm{Ce}_{10} \mathrm{Ni}_{9}\left(\dot{T}_{\mathrm{C} 1}, T_{\mathrm{m} 3}=1300^{\circ} \mathrm{C}\right)$ in the amorphous as-quenched state concentration points of $\mathrm{Ce}$ (bright points) are found (figure 1(c)). The measured concentration of $\mathrm{Ce}$ in this area is clearly larger (L-x-ray: $>10$ at.\%) than the mean concentration (L-x-ray: 9.8 at.\%) of the alloy. But the diffuse diffraction scattering of a TEM picture of the as-quenched state shows it to be fully amorphous (figure 1(d)). Such concentration points of $\mathrm{Ce}$ in $\mathrm{Al}_{84} \mathrm{Ce}_{6} \mathrm{Ni}_{10}$ materials are not found in the BSE picture of the ESEM (figure 1(e)).

In spite of the different results of the as-quenched state structure, no differences during the melting process (flow process, melting residue) have been observed. 
(a)

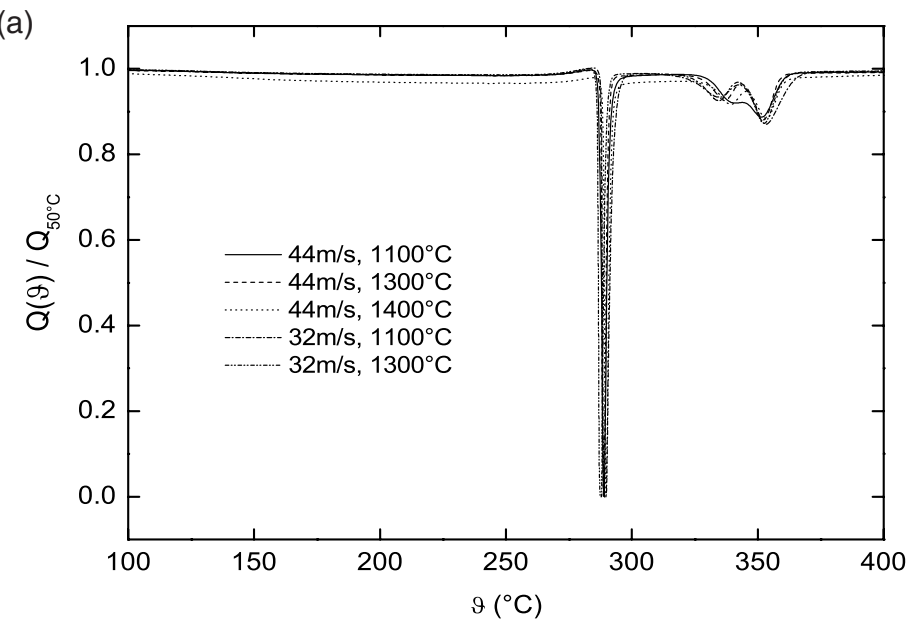

(b)

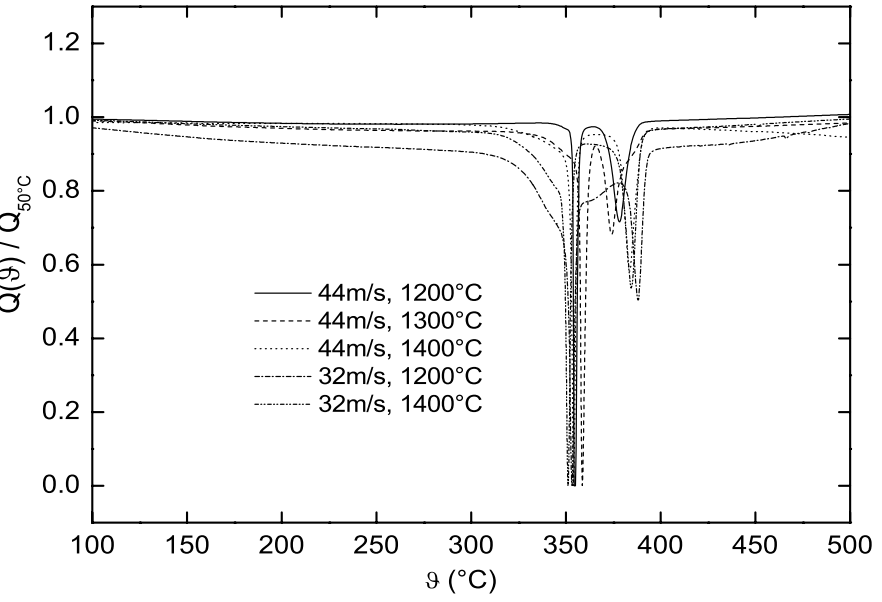

Figure 2. (a) The DSC curves ( $20 \mathrm{~K} \mathrm{~min}^{-1}$ heating rate) of $\mathrm{Al}_{84} \mathrm{Ce}_{6} \mathrm{Ni}_{10}$ of different production conditions, normed to $50{ }^{\circ} \mathrm{C}$. (b) The DSC curves $\left(20 \mathrm{~K} \mathrm{~min}^{-1}\right.$ heating rate) of $\mathrm{Al}_{81} \mathrm{Ce}_{10} \mathrm{Ni}_{9}$ of different production conditions.

\subsection{Thermal heat treatment at constant heating rates}

The ribbons are investigated with different thermal treatments (continuous heating between 2 and $25 \mathrm{~K} \mathrm{~min}^{-1}$ as well as isothermal heating).

3.2.1. Calorimetric measurements on $\mathrm{Al}_{84} \mathrm{Ce}_{6} \mathrm{Ni}_{10}$ and $\mathrm{Al}_{81} \mathrm{Ce}_{10} \mathrm{Ni} \mathrm{i}_{9}$. The DSC heating curves at $20 \mathrm{~K} \mathrm{~min}^{-1}$ for the different possibilities of $\dot{T}_{\mathrm{C} 1}$ and $\dot{T}_{\mathrm{C} 2}$ as well as $T_{\mathrm{m} 1}, T_{\mathrm{m} 3}$, and $T_{\mathrm{m} 4}$ of the $\mathrm{Al}_{84} \mathrm{Ce}_{6} \mathrm{Ni}_{10}$ materials are shown in figure 2(a). There are small differences in the amount of heat flow for the first crystallization peak. The temperature of the first peak does not vary for different production conditions. The second crystalline process shows a two-peak structure. There exist small differences in the heat flow and the position of the temperature minima for the different production conditions. The melt temperature of $T_{\mathrm{m} 1}=1100^{\circ} \mathrm{C}$ and the dwelltime of the melt were obviously not enough to obtain sufficient decomposition of the solid components of the ingots and sufficient mixing of the melt. The melt temperature of the $\mathrm{Al}_{4} \mathrm{Ce}$ 
phase in the equilibrium is given by [18] with $1236^{\circ} \mathrm{C}$. $\mathrm{All}^{\mathrm{Al}}{ }_{84} \mathrm{Ce}_{6} \mathrm{Ni}_{10}$ materials show a small region of SL (endothermal effect) followed by a strong exothermal peak. The form and the intensity of this peak hint at a eutectic crystallization at temperatures smaller than $280^{\circ} \mathrm{C}$. The first crystalline structure is stable only up to about $340^{\circ} \mathrm{C}$ and decays in two directly batched processes. In figure 2(b) the DSC heating curves are shown for $\mathrm{Al}_{81} \mathrm{Ce}_{10} \mathrm{Ni}_{9}$ materials. The $\mathrm{Al}_{81} \mathrm{Ce}_{10} \mathrm{Ni}_{9}$ materials show differences in the heat flow and the onset temperature depending on the melt temperature $T_{\mathrm{m} 2}, T_{\mathrm{m} 3}$ or $T_{\mathrm{m} 4}$ and the cooling rate $\dot{T}_{\mathrm{C} 1}$ or $\dot{T}_{\mathrm{C} 2}$. The higher Ce concentration reacts more sensitively to the formation of the amorphous structure and the adjacent crystallization. A reason could be that this concentration is located at the head of the existence of the amorphous state under this production condition. The transformation takes place without a visible transition to the SL (glass transition). No endothermal heating process was observed in the DSC curves from the beginning of the heating. We were unable to determine the reason for this decrease, but we can assume that already existing nuclei as well as crystals contributed to the advance of the crystallization. For the ribbons with the highest melting temperature relaxation is scarcely observed and the crystallization (an intensive exothermal heat flow) is observable first. The crystallization process begins with small heat transformation. The main effect is a strong exothermal effect at about $350{ }^{\circ} \mathrm{C}$, followed by another exothermal peak. The shift of the first peak depends on the production conditions and is smaller than $10^{\circ}$. However, the last peak shows a stronger dependence on the melting and cooling conditions. DSC studies are performed at heating rates of 1, 2, 5 and $20 \mathrm{~K} \mathrm{~min}^{-1}$ for the material $\mathrm{Al}_{84} \mathrm{Ce}_{6} \mathrm{Ni}_{10}\left(1400^{\circ} \mathrm{C} / 44 \mathrm{~m} \mathrm{~s}^{-1}\right)$. A succession of exo- and endothermal effects are observed. It is generally accepted that the calorimetrically measured heat flow rate $(\mathrm{d} Q / \mathrm{d} t(\mathrm{~W} / \mathrm{g}))$ is proportional to the change of the transformed volume fraction $(\alpha)$. In the case of constant heating rate experiments, the rate of transformation is given by

$$
\frac{\partial \alpha}{\partial t}=\frac{\partial \alpha}{\partial T} \cdot \dot{T}=\frac{\partial Q}{\partial t} \cdot \Delta Q^{-1}
$$

( $\dot{T}$, heating rate; $\Delta Q$, the heating obtained after total transformation). Using the definition of the specific heat capacity at constant pressure the difference (first minus second run) $\Delta c_{p}$ can be calculated for constant heating rates:

$$
\Delta c_{p}=\frac{\partial Q^{\prime}}{m \cdot \partial T}=\frac{\partial Q^{\prime}}{m \cdot \partial t \cdot \dot{T}}
$$

The specific heat $(C(\mathrm{~J} / \mathrm{g}))$ was determined by integration of the measured heat flow rate curves across the corresponding peak:

$$
C=\int_{t_{1}}^{t_{2}} \frac{\partial Q}{\mathrm{~d} t} \cdot \mathrm{d} t\left(\frac{\mathrm{J}}{\mathrm{g}}\right) .
$$

The $\Delta c_{p}$-convention was chosen to compare measurements at different heating rates. In figure 3(a) the change of the specific heat capacity difference $\left(\Delta c_{p}\right)$ is shown in the temperature interval between 200 and $400^{\circ} \mathrm{C}$ for 2 and $20 \mathrm{~K} \mathrm{~min}^{-1}$. A slight exothermal effect due to relaxation above $120^{\circ} \mathrm{C}$ is only visible at a rate of $20 \mathrm{~K} \mathrm{~min}^{-1}$. The endothermal glass transition is closely followed by a eutectic-like crystallization process amounting to a specific heat of $-(76 \pm 2) \mathrm{J} \mathrm{g}^{-1}$; the corresponding temperatures are $\vartheta_{\mathrm{GT}}=268^{\circ} \mathrm{C}$ and $\vartheta_{x}=286^{\circ} \mathrm{C}$ when heating at $20 \mathrm{~K} \mathrm{~min}^{-1}$. At even higher temperatures, two further overlapping transitions are recorded that amount to a specific heat of $-46 \mathrm{~J} \mathrm{~g}^{-1}$ at $20 \mathrm{~K} \mathrm{~min}^{-1}$.

The amorphous states of $\mathrm{AlCe}_{10} \mathrm{Ni}_{9}$ are more stable, and only at temperatures above $350^{\circ} \mathrm{C}$ do they transform into the crystalline state without the existence of an SL. In figure 3(b) the DSC curves of 5 and $20 \mathrm{~K} \mathrm{~min}^{-1}$ are compared for the materials produced at $1400{ }^{\circ} \mathrm{C} / 44 \mathrm{~m} \mathrm{~s}^{-1}$. The intensive exothermal reaction is like a eutectic crystallization for both heating rates. 
(a)

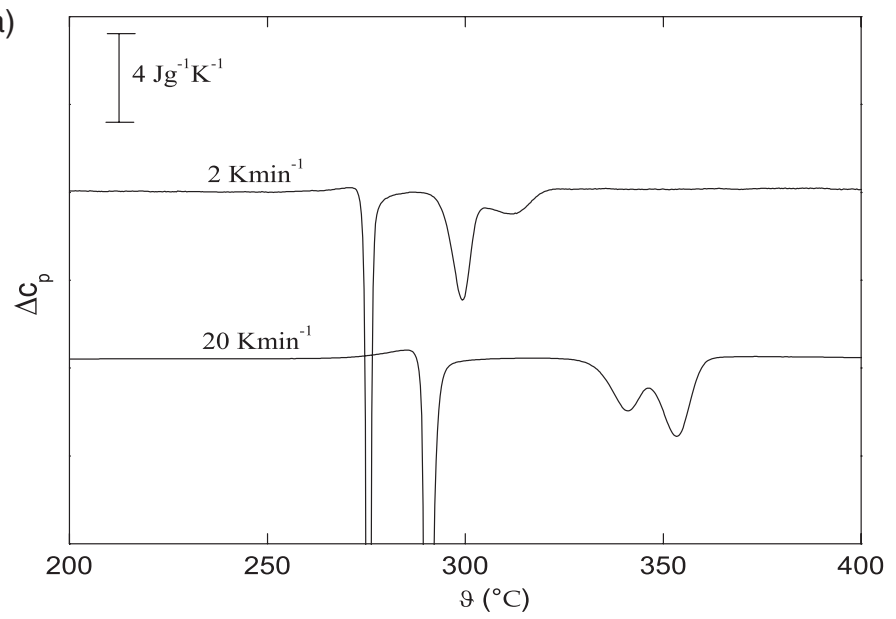

(b)

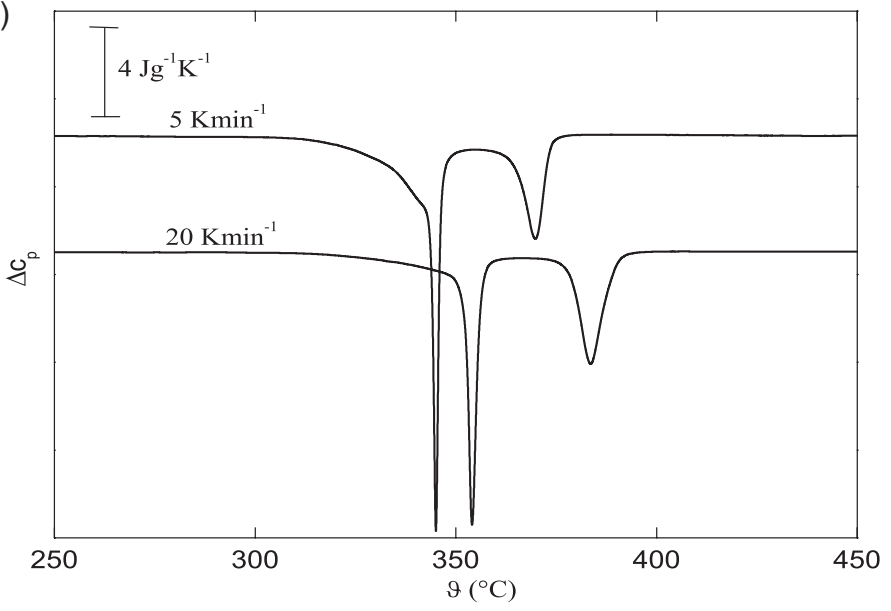

Figure 3. (a) The specific heat capacity curves of $\mathrm{Al}_{84} \mathrm{Ce}_{6} \mathrm{Ni}_{10}$ at 2 and $20 \mathrm{~K} \mathrm{~min}^{-1}$ heating rates in the temperature interval of $200-400{ }^{\circ} \mathrm{C}$. (b) The specific heat capacity curves of $\mathrm{Al}_{81} \mathrm{Ce}_{10} \mathrm{Ni}_{9}$ at 5 and $20 \mathrm{~K} \mathrm{~min}^{-1}$ heating rates in the temperature interval of $250-450{ }^{\circ} \mathrm{C}$.

A TEM image [19] of this state shows a eutectic-like structure. Of special interest is the beginning of the transformation. The crystallization begins with another process, clearly seen at $5 \mathrm{~K} \mathrm{~min}^{-1}$. This behaviour has been observed for materials forming $\mathrm{NC}$ of fcc- $\alpha$-Al [1, 20]. But in contrast to other amorphous materials here the crystallization begins at fairly high temperatures. The crystallization of the rest of the amorphous matrix follows immediately. At about $370^{\circ} \mathrm{C}$ another exothermal transformation appears. From the DSC results is not clear why the decomposition in both materials takes place in such different manners.

3.2.2. ER measurements on $\mathrm{Al}_{84} \mathrm{Ce}_{6} N i_{10}$ and $\mathrm{AlC} \mathrm{e}_{10} \mathrm{Ni} i_{9}$. The heating curves of the $\mathrm{ER}$ and the associated TCR curves between $\mathrm{RT}$ and $600{ }^{\circ} \mathrm{C}\left(5 \mathrm{~K} \mathrm{~min}{ }^{-1}\right.$ heating rate $)$ for $\mathrm{Al}_{84} \mathrm{Ce}_{6} \mathrm{Ni}_{10}$ materials show small differences for the different melting conditions as well as in the DSC experiments. It seems that the size of the measured effect, the change of the ER of the different processes, does not agree with the change of the heat flow rate of the DSC curves initially (see figures 4(a)-(d) for $44 \mathrm{~m} \mathrm{~s}^{-1}$ at $T_{\mathrm{m} 1}, T_{\mathrm{m} 4}$ and for $30 \mathrm{~m} \mathrm{~s}^{-1}$ at $T_{\mathrm{m} 1}$ and $T_{\mathrm{m} 3}$ ). A more detailed 

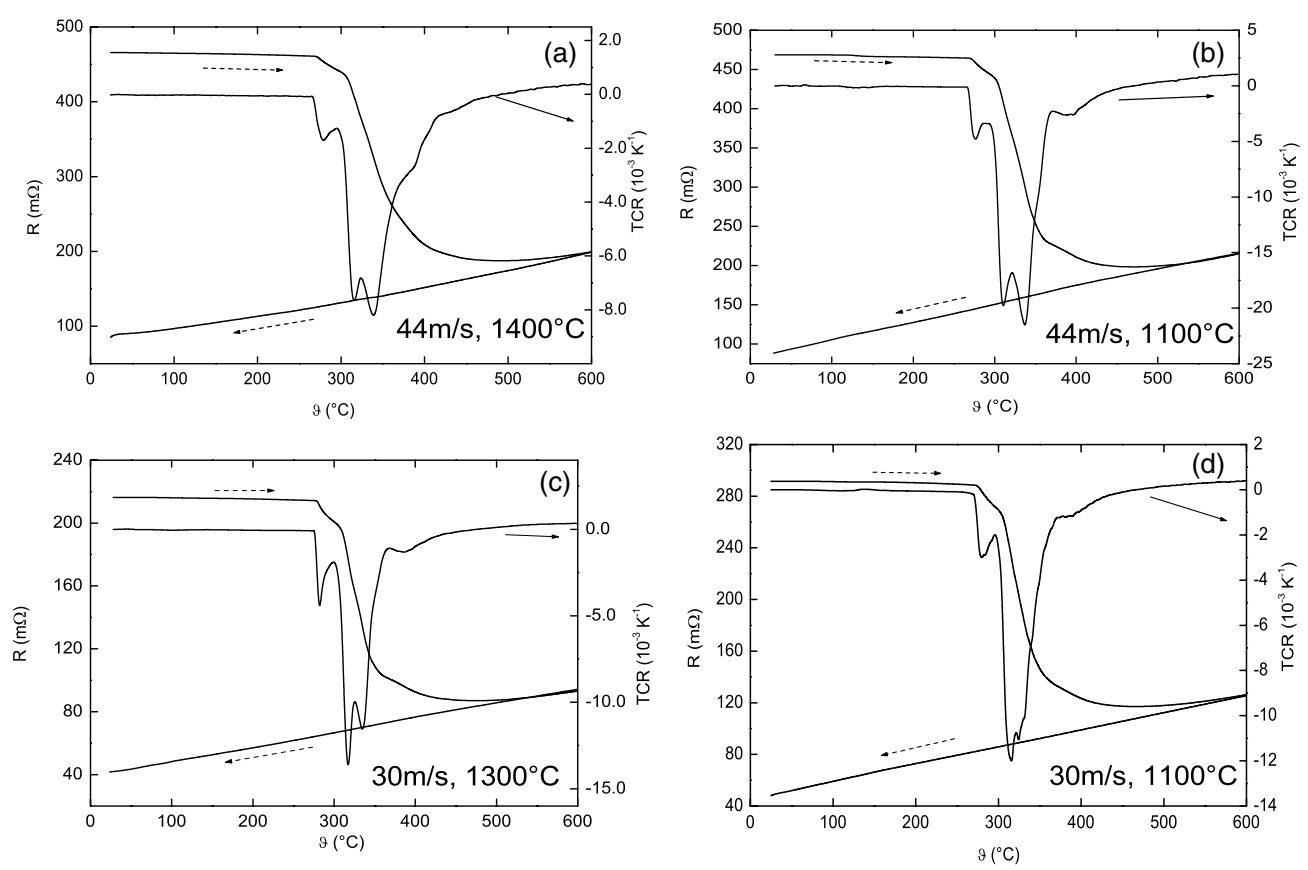

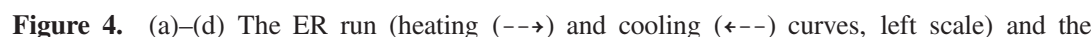
TCR curves $\left(\longrightarrow\right.$, right scale) of $\mathrm{Al}_{84} \mathrm{Ce}_{6} \mathrm{Ni}_{10}$ of different production conditions at $10 \mathrm{~K} \mathrm{~min}^{-1}$ heating rate.

comparison shows that the sensitivity of the ER and calorimetric measurements is different during the structural transformation from amorphous to crystalline. The first crystallization begins with a sharp decrease. The two following transformations lead to a strong decrease of the ER. The cooling curves in the figures only show the temperature effect of the crystalline final state. The observation of the SL during the ER measurement is not always easy. For the material produced at $44 \mathrm{~m} \mathrm{~s}^{-1} / 1300^{\circ} \mathrm{C}$ an interesting ER run was found (figures 5(a)(d)). This ribbon shows the best quality from all $\mathrm{Al}_{84} \mathrm{Ce}_{6} \mathrm{Ni}_{10}$ materials in terms of flexibility, uniformity of the thickness and width of the ribbon. The ER of this ribbon shows an increase in a small temperature interval, beginning at about $276^{\circ} \mathrm{C}$. The maximum value is at about $279{ }^{\circ} \mathrm{C}$. During the following crystallization the ER decreases strongly as in the other materials. Four different samples of this material are heated to temperatures where clear structural changes occur. The ER run of the heating (solid lines) and the cooling (dashed lines) curves and the TCR curves are shown in figures 5(a)-(d). The small linear decrease down to $271{ }^{\circ} \mathrm{C}$ grows out of the superposition of the structure relaxation (decreasing) and the temperature effect (increasing). Applying the Matthies rule [21] and assuming a linear temperature growth we conclude that the decrease of the ER at the beginning of the experiment is an indicator to relaxation process in this material yield that the decrease of the ER at the beginning of the heating the chain of relaxation. The remarkable deviation from linearity begins at about $271^{\circ} \mathrm{C}$. The ER increases rather erratically before it steeply decreases. The DSC curve here shows the endothermal heat development. We interpret this as the SL transition. There are two effects that contribute to a change in the ER during the glass transition. First, the disorder increases the ER, and second, the increase of the viscosity changes the volume and allows the material to flow more easily under the weight force. The last effect was observed in several experiments when the length 

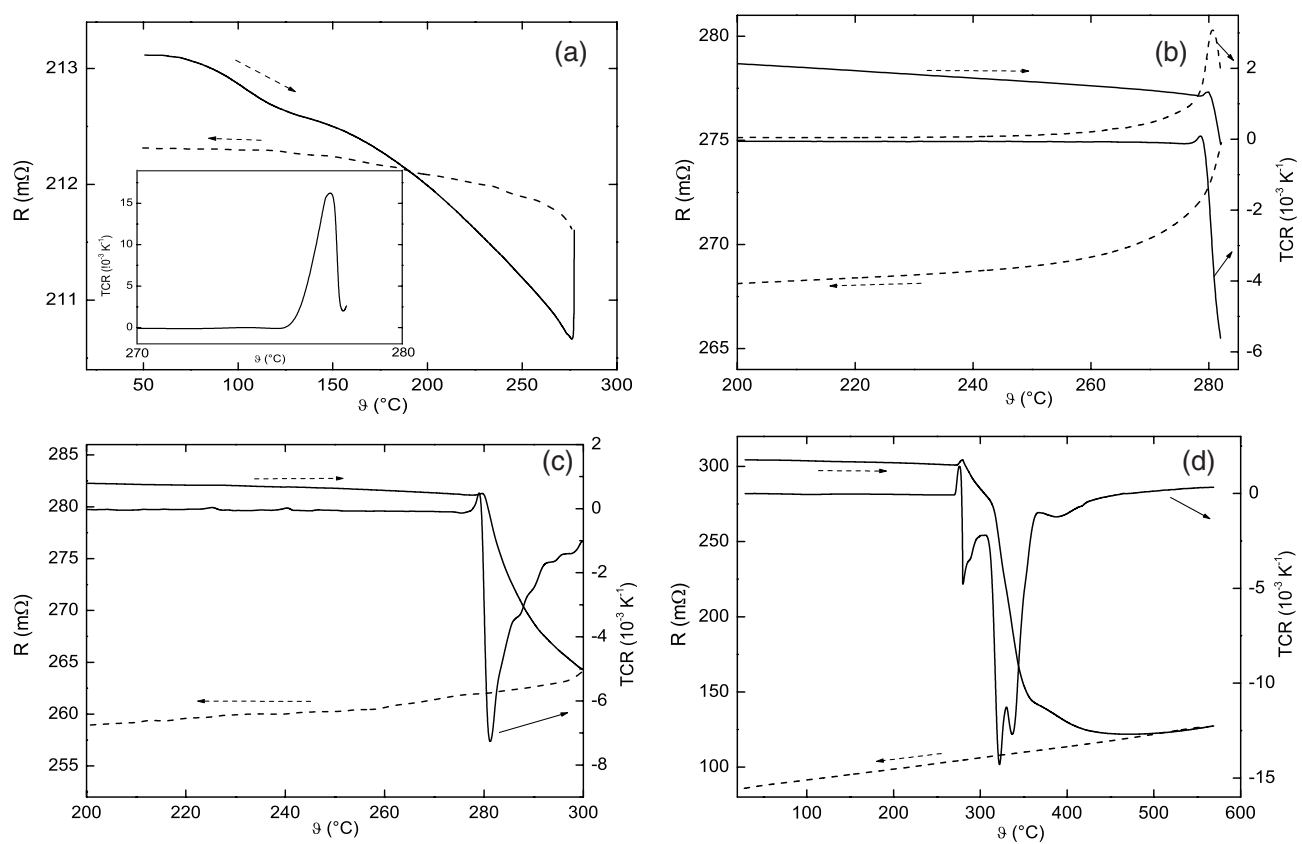

Figure 5. (a)-(d) The ER run (heating $(--\rightarrow)$ and cooling $(\leftarrow--)$ curves) and the TCR $(\longrightarrow)$ curves of $\mathrm{Al}_{84} \mathrm{Ce}_{6} \mathrm{Ni}_{10}$ produced at $1300{ }^{\circ} \mathrm{C} / 44 \mathrm{~m} \mathrm{~s}^{-1}$ up to different heating temperatures for the XRD investigation.

of the ribbons was different. Therefore the dimensions of the ER samples are chosen to be similar in each experiment. The results are shown in figures 5(a)-(d). The samples are heated up to $277.5^{\circ} \mathrm{C}$ (a), $282^{\circ} \mathrm{C}$ (b), $300^{\circ} \mathrm{C}$ (c) and $570^{\circ} \mathrm{C}$ (d) and immediately cooled down after reaching this temperature.

The glass temperature $\left(T_{\mathrm{g}}\right)$ determined from the strong increase of the ER measurement and the tangent method of the DSC curves are in good agreement. The decrease of the ER begins at about $279^{\circ} \mathrm{C}$ in the same abrupt manner. This event marks the beginning of the crystallization. The change of the ER for the first crystallization process is very sharp. This is typical for eutectic solidification. However, the drop of the ER is small compared to the whole ER change during the heating up to $600^{\circ} \mathrm{C}$. The cooling curves show an interesting behaviour-for heating up to $276{ }^{\circ} \mathrm{C}$ (SL), they show a negative temperature coefficient (figure 5(a)). The increase of the ER at the beginning of the cooling is the residual effect of the SL. The weakened increase that follows could be a reversible part of the relaxation. With the beginning of the crystallization the ER decreases linearly during the cooling because of the positive temperature coefficient (TCR) for the crystalline structure of the Al-Ce-Ni phases that are formed (figures 5(b)-(d)).

The heat flow of the DSC experiments is more sensitive to the phase transformation. The ER on the other hand is more sensitive to the atom rearrangements in the materials. Therefore, our result indicates that during the beginning of the crystallization the atoms do not change their position when the temperature is increased; the formation of stable phases takes place. This coincides with rearrangements of the atoms into the new stable grain structure.

The constant heating curves of the ER measurement of the $\mathrm{Al}_{81} \mathrm{Ce}_{10} \mathrm{Ni}_{9}$ materials for different ribbons are shown in figures 6(a)-(d). The ER changes quickly in a relative narrow temperature interval $\left(300-400^{\circ} \mathrm{C}\right)$. The different transitions are not clearly separated. Although different transformations take place these are not easily distinguishable compared to 

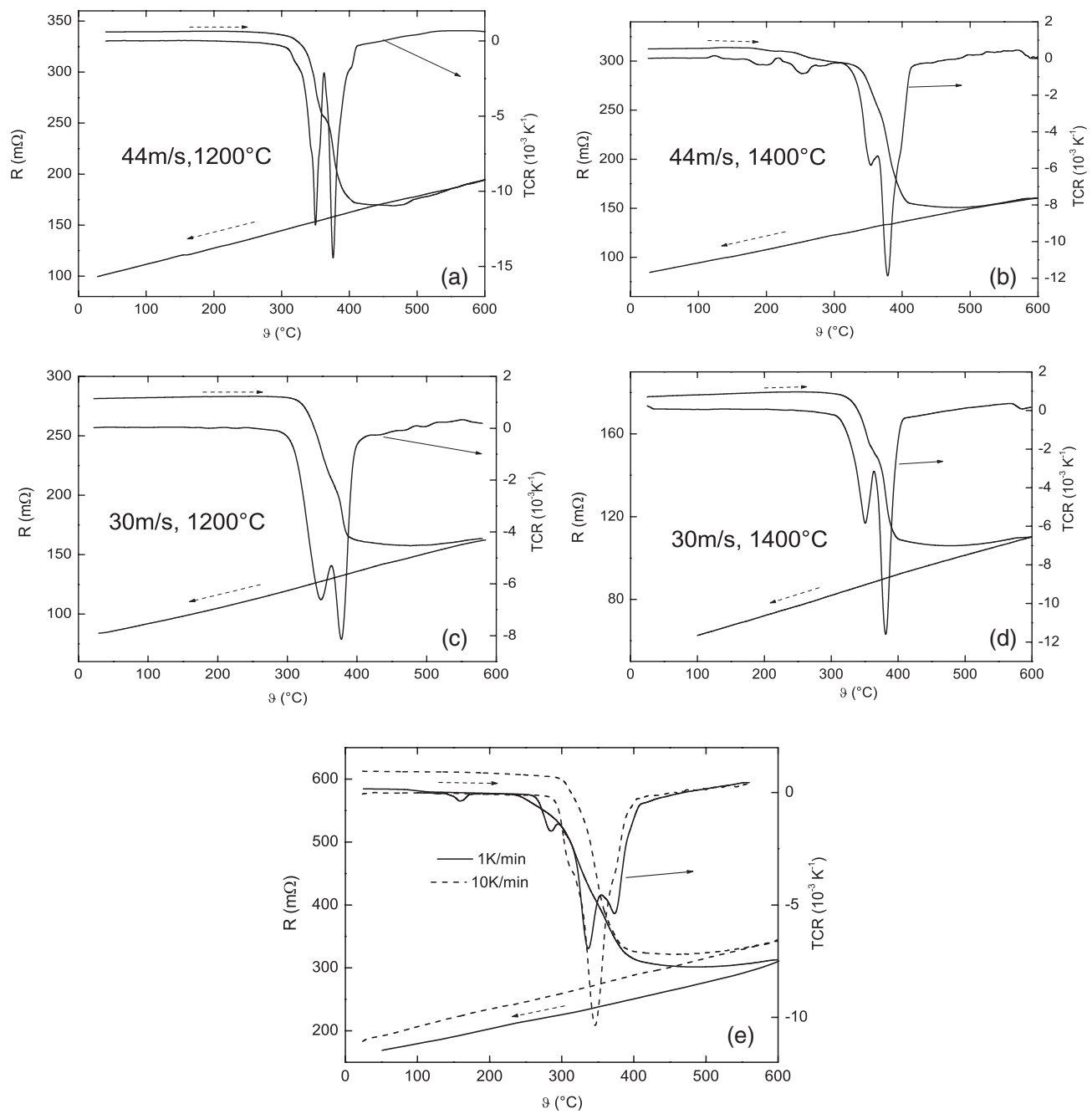

Figure 6. (a)-(d) The ER run (heating $(--\rightarrow)$ and cooling $(\leftarrow--)$ curves) and the TCR $(\rightarrow)$ curves of $\mathrm{Al}_{81} \mathrm{Ce}_{10} \mathrm{Ni}_{9}$ of different production conditions at $10 \mathrm{~K} \mathrm{~min}^{-1}$ heating rate. (e) The ER run (heating $(--\rightarrow)$ and cooling $(\leftarrow--)$ curves) and the TCR $(\longrightarrow)$ curves of $\mathrm{Al}_{81} \mathrm{Ce}_{10} \mathrm{Ni}_{9}\left(1300{ }^{\circ} \mathrm{C} / 44 \mathrm{~m} \mathrm{~s}^{-1}\right)$ at 1 and $10 \mathrm{~K} \mathrm{~min}^{-1}$ heating rate.

the DSC curves. A good repeatability is found for the peak temperatures but not in relation to the magnitude of the ER in the different parts of the transformation. These results are consistent if inequalities are formed in the ribbons during the cooling. Therefore, the measurements were repeated several times. The best repeatability was obtained for the material produced with $44 \mathrm{~m} \mathrm{~s}^{-1} / 1300^{\circ} \mathrm{C}$. In figure $6(\mathrm{e})$ the run of ER of this material together with the TCR curves of 1 and $10 \mathrm{~K} \mathrm{~min}^{-1}$ heating are shown. Diffraction as well as TEM investigations were performed for that material to obtain a better understanding of the crystallization process.

\subsection{XRD measurements on $\mathrm{Al}_{84} \mathrm{Ce}_{6} \mathrm{Ni}_{10}$ and $\mathrm{Al}_{81} \mathrm{Ce}_{10} \mathrm{Ni}_{9}$}

The diffuse diffraction pattern of the as-quenched state of different production conditions is shown in figures 1(a) and (b). The influence of the melting temperature $\left(T_{\mathrm{m}}\right)$ is larger than the 
(a)

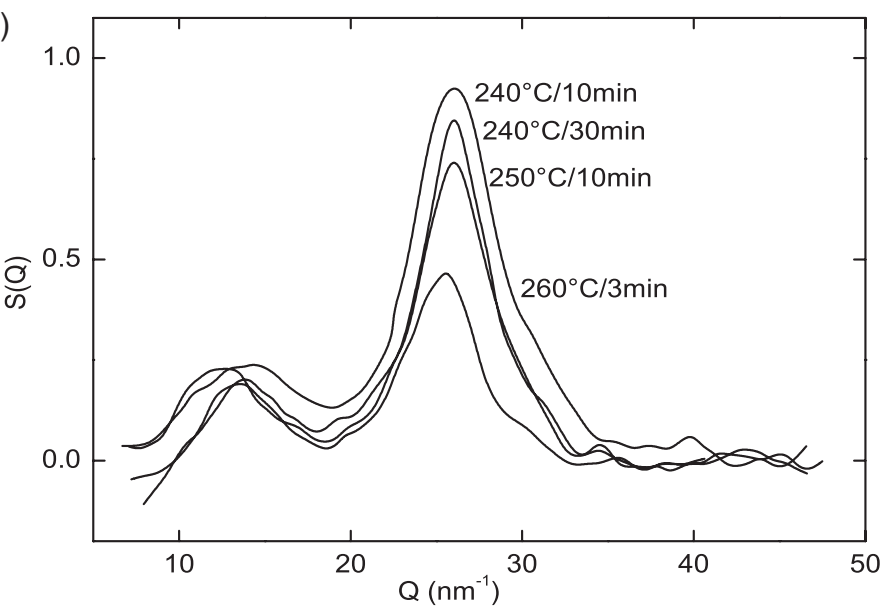

(b)

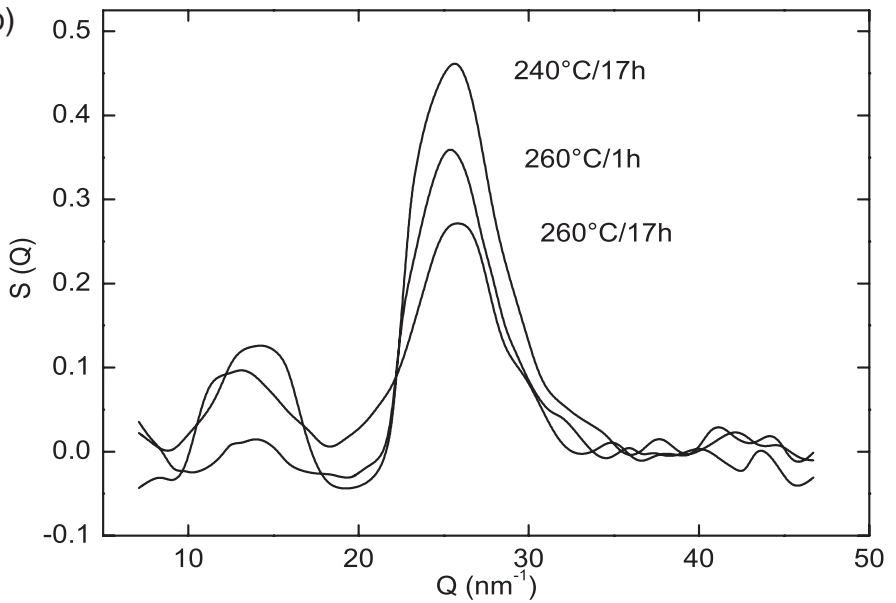

Figure 7. (a) The $S(Q)$ development of the amorphous structure of $\mathrm{Al}_{84} \mathrm{Ce}_{6} \mathrm{Ni}_{10}$ $\left(1300^{\circ} \mathrm{C} / 44 \mathrm{~m} \mathrm{~s}^{-1}\right)$ after different isothermal ageings. (b) The $S(Q)$ development of the amorphous structure of $\mathrm{Al}_{81} \mathrm{Ce}_{10} \mathrm{Ni}_{9}\left(1300^{\circ} \mathrm{C} / 44 \mathrm{~m} \mathrm{~s}^{-1}\right)$ after different isothermal ageings.

cooling rate $\left(\dot{T}_{\mathrm{C}}\right)$. As a result of the relaxation the structure factor $S(Q)$ changes during the isothermal ageing; see figure 7(a) for $\mathrm{Al}_{84} \mathrm{Ce}_{6} \mathrm{Ni}_{10}$ and figure 7(b) for $\mathrm{Al}_{81} \mathrm{Ce}_{10} \mathrm{Ni}_{9}$ materials. For $\mathrm{Al}_{84} \mathrm{Ce}_{6} \mathrm{Ni}_{10}$ the intensity of $S(Q)$ decreases with the higher ageing temperatures, although in the XRD curves after heating up to $276^{\circ} \mathrm{C}$ (figure $8(\mathrm{a})$ ) and isothermal ageing of $260^{\circ} \mathrm{C} / 3$ min (figure $8(b)$ ) no clear signs of crystallization were found. The decrease of the intensity can be interpreted as a decrease of the amorphous portion due to the formation of smaller ordered structures. The main peaks are shifted slightly to a value $Q=26.5 \mathrm{~nm}^{-1}$ compared with the as-quenched state $\left(25.8 \mathrm{~nm}^{-1}\right)$. This is a hint that the atomic distance of $0.278 \mathrm{~nm}$ changes minor during the relaxation. This change of the main peak suggests an increase of nearest neighbour $\mathrm{Al}-\mathrm{Al}$ distances, evaluated from atomic radii, $r=0.286 \mathrm{~nm}$. The Al-Ni distance is $0.269 \mathrm{~nm}$ and the $\mathrm{Ce}-\mathrm{Ce}$ distance is in the order of $0.362 \mathrm{~nm}$. Therefore the prepeak $\left(Q=13.8 \mathrm{~nm}^{-1}\right.$ ) indicates the existence of $\mathrm{Al}-\mathrm{Ce}$ with a atomic distance of $0.323 \mathrm{~nm}$. The coordination number for $\mathrm{Al}-\mathrm{Al}$ is much larger than that of the Al-Ce. The shoulder on the right side of the main peak could indicate a near-range order of Al-Ni atoms. 

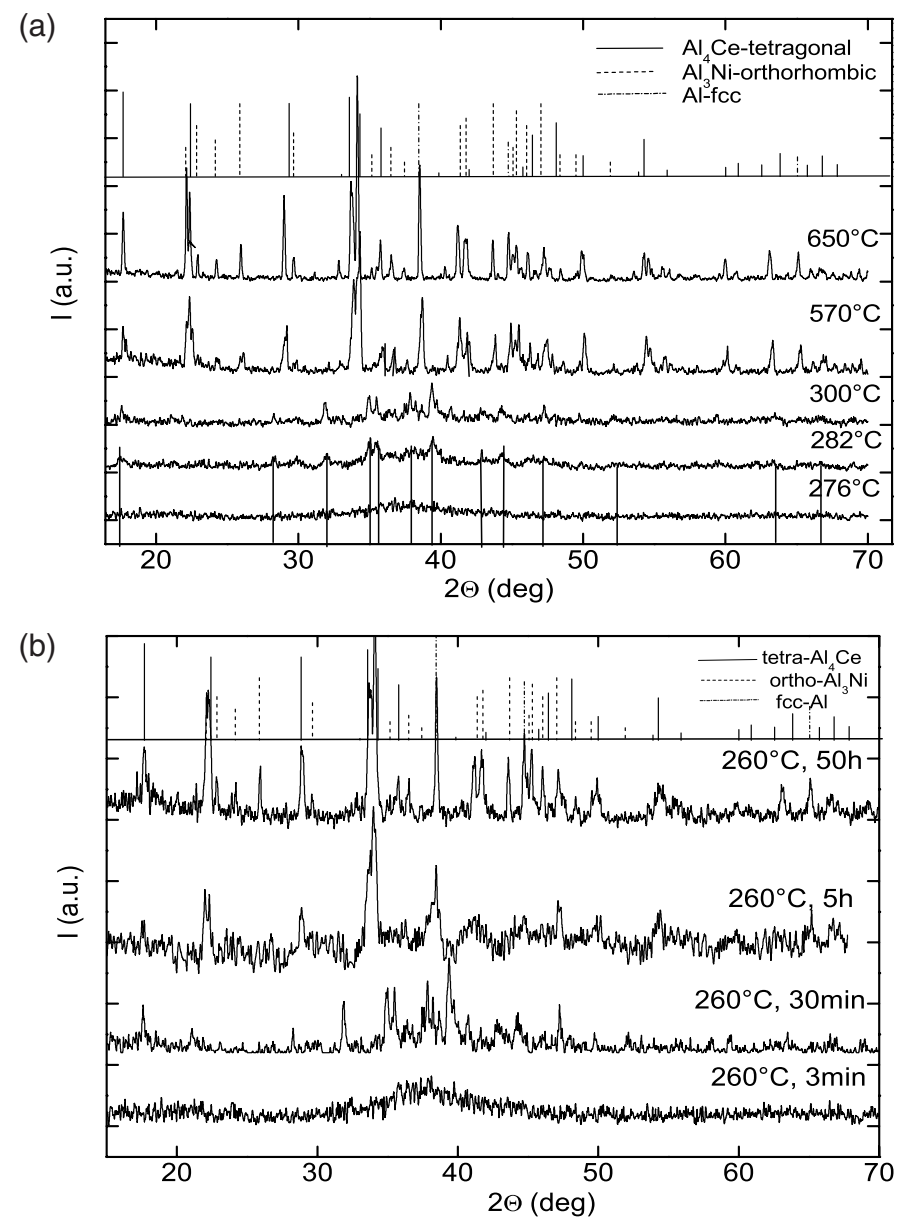

\footnotetext{
Figure 8. (a) The XRD development of the crystalline structure of $\mathrm{Al}_{84} \mathrm{Ce}_{6} \mathrm{Ni}_{10}$ $\left(130{ }^{\circ} \mathrm{C} / 44 \mathrm{~m} \mathrm{~s}^{-1}\right)$ up to different heating temperatures (see figures 5(a)-(d)); at the top is the calculated diffraction pattern of $\mathrm{fcc}(\alpha)-\mathrm{Al}$ (dash-dot), tetragonal- $\mathrm{Al}_{4} \mathrm{Ce}$ (solid) and orthorhombic- $\mathrm{Al}_{3} \mathrm{Ni}$ (dashed). (b) The XRD development of the crystalline structure of $\mathrm{Al}_{84} \mathrm{Ce}_{6} \mathrm{Ni}_{10}\left(1300{ }^{\circ} \mathrm{C} / 44 \mathrm{~m} \mathrm{~s}^{-1}\right)$ after isothermal ageing at $260{ }^{\circ} \mathrm{C}$; at the top is the calculated diffraction pattern of $\mathrm{fcc}(\alpha)-\mathrm{Al}$ (dash-dot), tetragonal- $\mathrm{Al}_{4} \mathrm{Ce}$ (solid) and orthorhombic- $\mathrm{Al}_{3} \mathrm{Ni}$ (dashed).
}

First evidence for crystallization in the XRD diagrams after constant heating $\left(5 \mathrm{~K} \mathrm{~min}^{-1}\right)$ is visible in $\mathrm{Al}_{84} \mathrm{Ce}_{6} \mathrm{Ni}_{10}$ materials at $282^{\circ} \mathrm{C}$ (figure 8(a)). The weak development of different crystalline structures indicates from the beginning very fine disperse crystalline structure as known from the eutectic crystallization. A correlation with a known ternary or binary phase was not found [22]. This phase exists at $300^{\circ} \mathrm{C}$ as well. Only at temperatures above $450{ }^{\circ} \mathrm{C}$ is the final stable phase structure observed. The diffraction pattern after heating up to $600^{\circ} \mathrm{C}$ is included in figure 8 (a). This is the final structure and the relatively sharp peaks at $650{ }^{\circ} \mathrm{C}$ imply a growth of the grain structure.

The structure development after isothermal ageing at $260^{\circ} \mathrm{C}$ (figure $8(\mathrm{~b})$ ) is visible at the beginning of the relaxation $\left(260^{\circ} \mathrm{C} / 3 \mathrm{~min}\right)$. At $260^{\circ} \mathrm{C} / 30 \mathrm{~min}$ the first crystalline structure is formed. At $260^{\circ} \mathrm{C} / 5 \mathrm{~h}$ the crystalline structure has changed into an $\mathrm{Al}_{4} \mathrm{Ce}$ phase and at $260^{\circ} \mathrm{C} / 50 \mathrm{~h}$ an additional $\mathrm{Al}_{3} \mathrm{Ni}$ phase could be identified [16, 23]. 

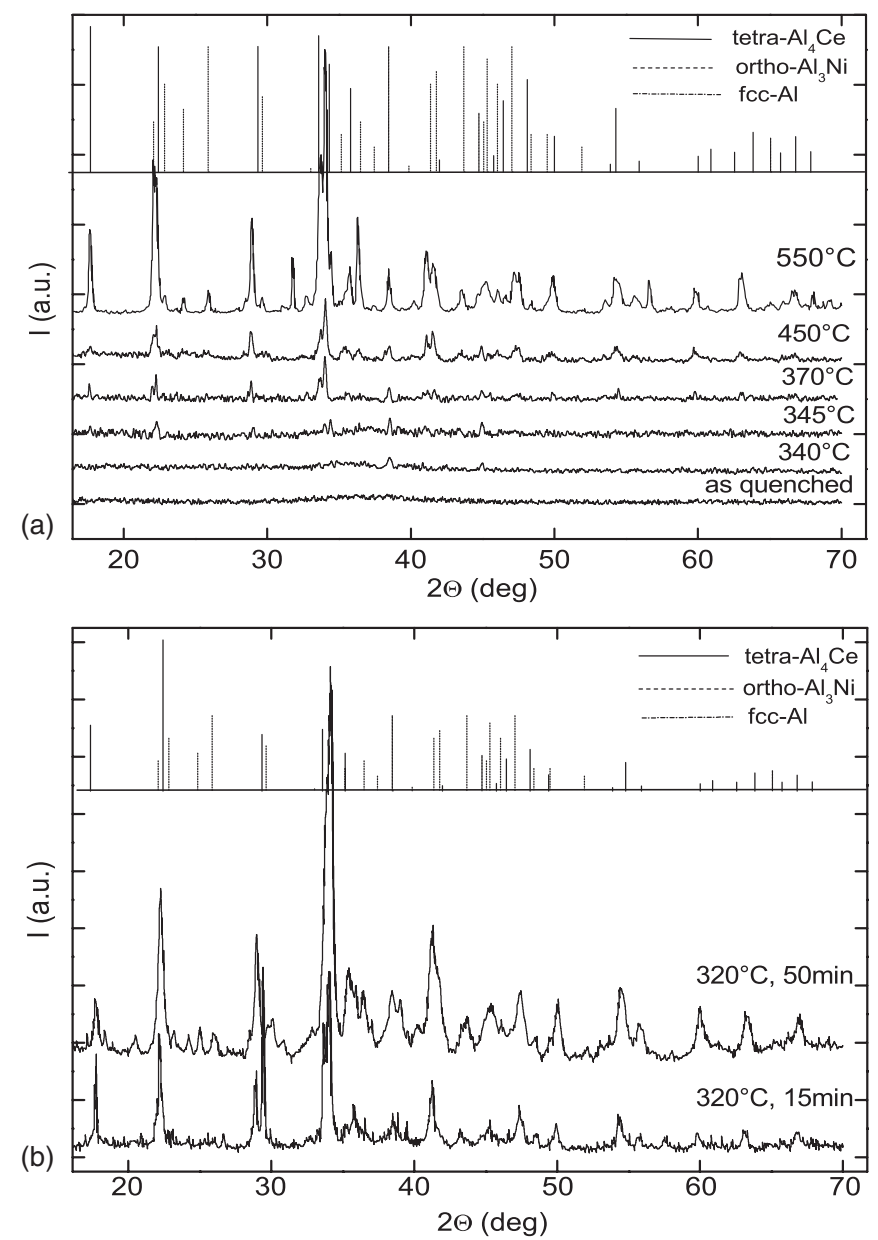

Figure 9. (a) The $\mathrm{XRD}$ development of the crystalline structure of $\mathrm{Al}_{81} \mathrm{Ce}_{10} \mathrm{Ni}_{9}$ $\left(1300^{\circ} \mathrm{C} / 44 \mathrm{~m} \mathrm{~s}^{-1}\right)$ up to different heating temperatures (see figure 3(b)); at the top is the calculated diffraction pattern of $\mathrm{fcc}(\alpha)-\mathrm{Al}$ (dash-dot), tetragonal- $\mathrm{Al}_{4} \mathrm{Ce}$ (solid) and orthorhombic- $\mathrm{Al}_{3} \mathrm{Ni}$ (dashed). (b) The XRD development of the crystalline structure of $\mathrm{Al}_{81} \mathrm{Ce}_{10} \mathrm{Ni}_{9}\left(1300{ }^{\circ} \mathrm{C} / 44 \mathrm{~m} \mathrm{~s}^{-1}\right)$ after isothermal ageing at $320{ }^{\circ} \mathrm{C} / 15 \mathrm{~min}$ and $50 \mathrm{~min}$, at the top the calculated diffraction pattern of fcc $(\alpha)-\mathrm{Al}$ (dash-dot), tetragonal- $\mathrm{Al}_{4} \mathrm{Ce}$ (solid) and orthorhombic- $\mathrm{Al}_{3} \mathrm{Ni}$ (dashed).

In the $\mathrm{Al}_{81} \mathrm{Ce}_{10} \mathrm{Ni}_{9}$ materials (figure 7(b)) the pre-peak shifts slightly after ageing to higher $Q$-values compared with the as-quenched state from 13.1 to $14.4 \mathrm{~nm}^{-1}$. This is a hint at rearrangements of the $\mathrm{Ce}$ atoms. The structure development of the $\mathrm{Al}_{81} \mathrm{Ce}_{10} \mathrm{Ni}_{9}$ material at a constant heating rate $\left(5 \mathrm{~K} \mathrm{~min}^{-1}\right)$ is shown in figure 9(a) (up to $550{ }^{\circ} \mathrm{C}$ ). Figure 9 (b) shows the structure development during the isothermal heating at $320^{\circ} \mathrm{C} / 15 \mathrm{~min}$ and $50 \mathrm{~min}$. Compared to the $\mathrm{Al}_{84} \mathrm{Ce}_{6} \mathrm{Ni}_{10}$ material, no regions of $\mathrm{SL}$ are found. After a strong relaxation in the amorphous matrix NC fcc- $\alpha$-Al begins to form, similar to other materials [24]. The residual amorphous matrix crystallizes in a tetragonal $\mathrm{Al}_{4} \mathrm{Ce}(\mathrm{Ni})$ phase with an unidentified structure. The $\mathrm{Al}_{3} \mathrm{Ni}$ phase is eliminated later from this phase and in the final state the (fcc) $\alpha-\mathrm{Al}$, the tetragonal $\mathrm{Al}_{4} \mathrm{Ce}$ and the orthorhombic $\mathrm{Al}_{3} \mathrm{Ni}$ phase are present just as in the $\mathrm{Al}_{84} \mathrm{Ce}_{6} \mathrm{Ni}_{10}$ material. 
(a)

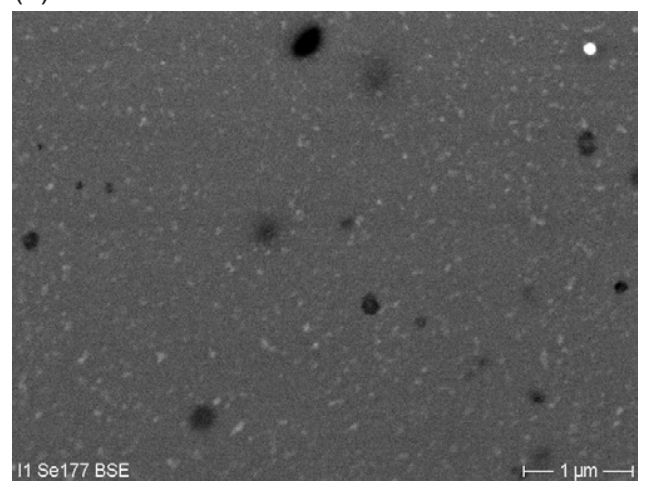

(c)

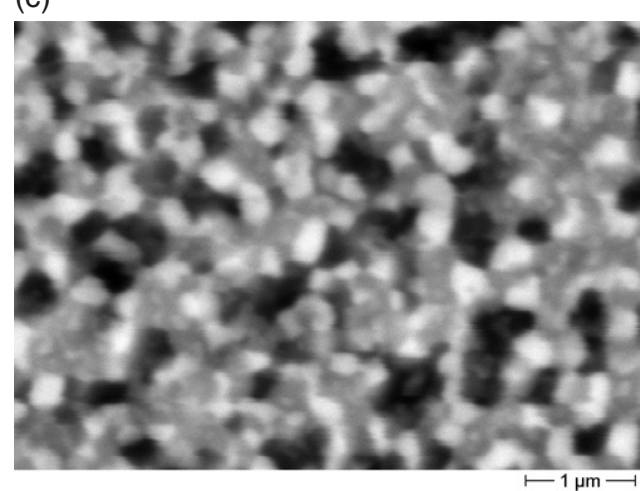

(b)

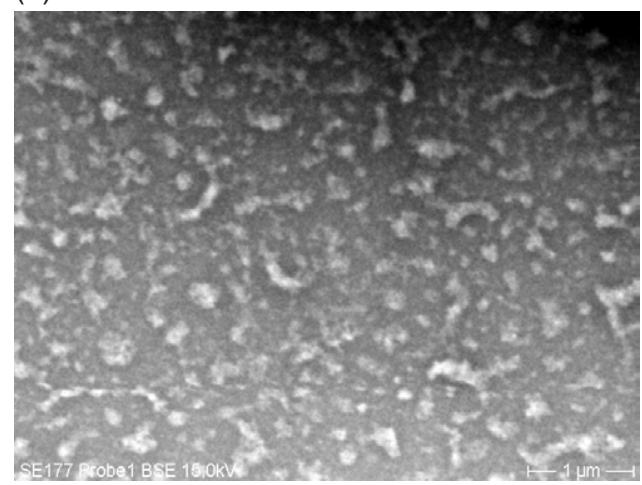

(d)

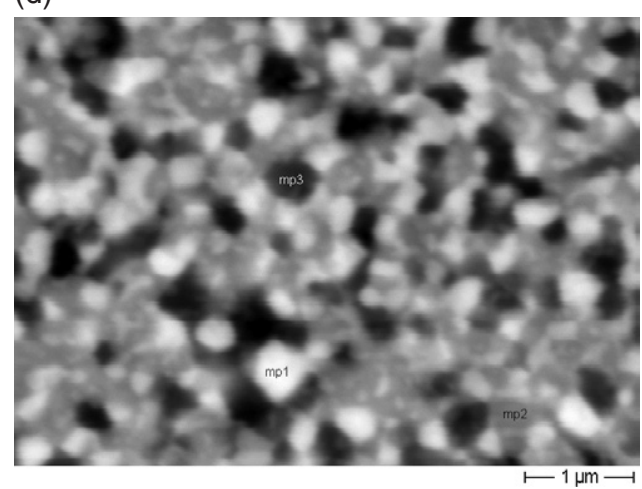

Figure 10. (a) The $\mathrm{BSE}$ pictures of $\mathrm{Al}_{84} \mathrm{Ce}_{6} \mathrm{Ni}_{10}\left(1300^{\circ} \mathrm{C} / 44 \mathrm{~m} \mathrm{~s}^{-1}\right)$ after heating to $282^{\circ} \mathrm{C}$ (see figures 5(b) and 8(a)). (b) The BSE pictures of $\mathrm{Al}_{84} \mathrm{Ce}_{6} \mathrm{Ni}_{10}\left(1300^{\circ} \mathrm{C} / 44 \mathrm{~m} \mathrm{~s}^{-1}\right.$ ) after isothermal ageing at $260^{\circ} \mathrm{C} / 30 \mathrm{~min}$ (see figure 8(b)). (c), (d) The BSE pictures of $\mathrm{Al}_{84} \mathrm{Ce}_{6} \mathrm{Ni}_{10}\left(1300^{\circ} \mathrm{C} / 44 \mathrm{~m} \mathrm{~s}^{-1}\right)$ after isothermal ageing at $500{ }^{\circ} \mathrm{C} / 1 \mathrm{~h}$ and $600^{\circ} \mathrm{C} / 1 \mathrm{~h}$.

\subsection{Electron microscope investigation}

The material $\mathrm{Al}_{84} \mathrm{Ce}_{6} \mathrm{Ni}_{10}$ is investigated by electron scanning microscopy. In the as-quenched state (figure 1(e)) a regular element distribution measured by $\mathrm{Al}$ (K-X-rays), 84.3 at.\%, $\mathrm{Ce}$ (L$\mathrm{x}$-rays), 6.1 at.\%, $\mathrm{Ni}$ (K-x-rays), 9.6 at.\% without visible concentration fluctuations is visible. The picture indicates a regular amorphous structure in this size interval. Figures 10(a) and (b) show the beginning of the formation of the crystalline structure after heating up to $282{ }^{\circ} \mathrm{C}$ and isothermal ageing at $260^{\circ} \mathrm{C} / 30 \mathrm{~min}$. Small fine precipitations form in the amorphous matrix at the beginning and a eutectic structure exists after $20 \mathrm{~h}$. After $500^{\circ} \mathrm{C} / 1 \mathrm{~h}$ (figure $10(\mathrm{c})$ ), $6 \mathrm{~h}$, and at $600^{\circ} \mathrm{C} / 1 \mathrm{~h}$ (figure $10(\mathrm{~d})$ ) a fine disperse structure is visible in BSE pictures of the ESEM. An EDX scan of the different regions (figure 10(d)) confirms the existence of the three different phases. The Ce concentration at measurement point ' $\mathrm{mp} 1$ ' is clearly higher ( $>9 \%)$ than at 'mp2' and 'mp3'. The concentration of $\mathrm{Ni}$ at 'mp1' was determined as $<8$ at $\%$. At 'mp2' the concentration of $\mathrm{Ni}$ is clearly higher $(>14$ at\%) than the mean concentration of $\mathrm{Ni}$ in the ingot. At 'mp3' the concentrations of $\mathrm{Ni}(<8$ at. $\%)$ and $\mathrm{Ce}(<2.4$ at. $\%)$ are clearly smaller than the mean concentration in the material.

The Ce rich regions $\left(\mathrm{Al}_{4} \mathrm{Ce}\right.$ phase) are not directly adjacent to the $\alpha$ - $\mathrm{Al}$ region. The $\mathrm{Al}_{3} \mathrm{Ni}$ phase appears as a reticular structure. Internally the $\mathrm{Al}$ phase and the $\mathrm{Al}_{4} \mathrm{Ce}$ phase are separated. One possible reason could be a temporally different decay of the ternary eutectic. 
(a)

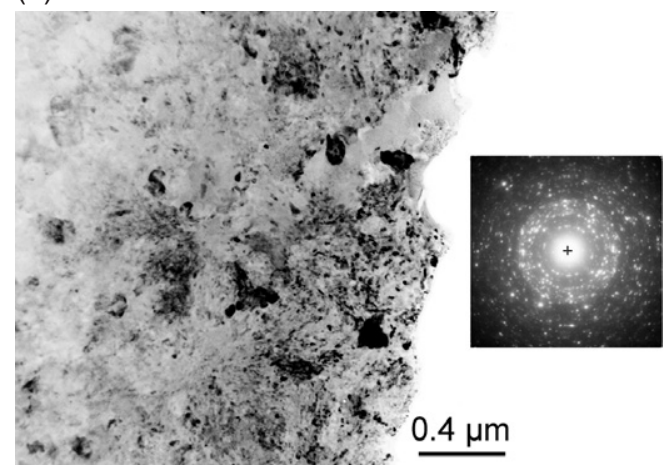

(b)

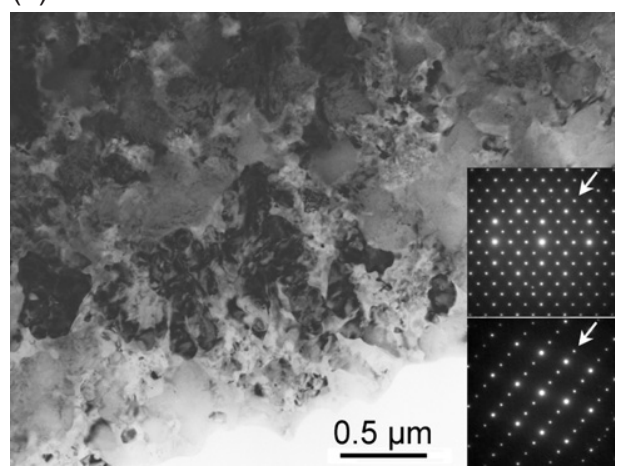

(c)

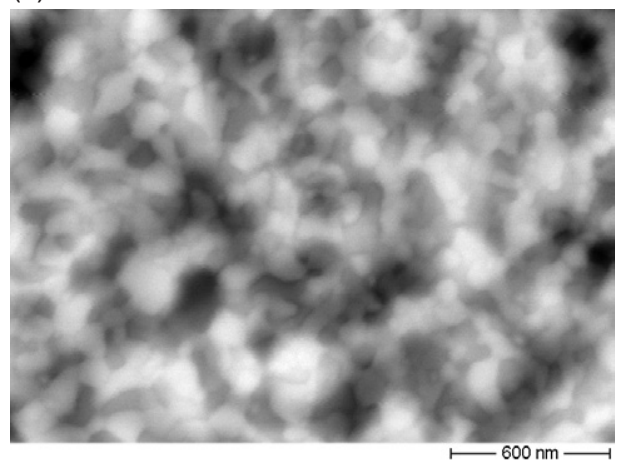

Figure 11. (a) The TEM pictures of $\mathrm{Al}_{81} \mathrm{Ce}_{10} \mathrm{Ni}_{9}\left(1300^{\circ} \mathrm{C} / 44 \mathrm{~m} \mathrm{~s}^{-1}\right)$ after isothermal ageing at $320^{\circ} \mathrm{C} / 15 \mathrm{~min}$ overview with diffraction pattern and a selected grain with diffraction pattern (the common axis is indicated by an arrow). (b) The TEM pictures of $\mathrm{Al}_{81} \mathrm{Ce}_{10} \mathrm{Ni}_{9}\left(1300{ }^{\circ} \mathrm{C} / 44 \mathrm{~m} \mathrm{~s}^{-1}\right)$, after isothermal ageing at $320^{\circ} \mathrm{C} / 50 \mathrm{~min}$, overview with diffraction pattern and diffraction pattern of selected grains (the common axis is indicated by an arrow). (c) The BSE pictures of $\mathrm{Al}_{81} \mathrm{Ce}_{10} \mathrm{Ni}_{9}\left(1300^{\circ} \mathrm{C} / 44 \mathrm{~m} \mathrm{~s}^{-1}\right)$ after isothermal ageing at $500^{\circ} \mathrm{C} / 1 \mathrm{~h}$.

In $\mathrm{Al}_{81} \mathrm{Ce}_{10} \mathrm{Ni}_{9}$ materials the crystallization begins with very small precipitations. After 15 min held at $320^{\circ} \mathrm{C}$, the TEM images (figure 11 (a)) show the existence of very small crystals (about $20 \mathrm{~nm}$ ) in a residual amorphous matrix. The nanocrystals are identified as $\alpha$ (fcc) $\mathrm{Al}$, whereas the bigger crystals correspond to $\mathrm{Al}_{11} \mathrm{Ce}_{3}$. After $50 \mathrm{~min}$ at $320^{\circ} \mathrm{C}$ (figure $11(\mathrm{~b})$ ), the precipitates have increased in size and in addition the phases $\mathrm{Al}_{3} \mathrm{Ni}$ and $\mathrm{Al}_{3} \mathrm{Ce}$ are shown in the diffractograms in figure 9(b). The BSE scanning pictures of the $\mathrm{AlCe}_{10} \mathrm{Ni}_{9}$ materials at $500{ }^{\circ} \mathrm{C} / 1 \mathrm{~h}$ (figure $11(\mathrm{c})$ ) and $6 \mathrm{~h}$ show not such strong interfaces between the different phases and the structure is more finely dispersed in comparison to the $\mathrm{AlCe}_{6} \mathrm{Ni}_{10}$.

\subsection{Isothermal heat treatment investigation}

3.5.1. Isothermal calorimetric studies. Isothermal calorimetric studies of the $\mathrm{AlCe}_{6} \mathrm{Ni}_{10}$ material between 200 and $325^{\circ} \mathrm{C}$ were limited to the first two hours of annealing. At 200 and $230^{\circ} \mathrm{C}$, only exothermal effects due to relaxation are recorded, which last for about $30 \mathrm{~min}$. At $260^{\circ} \mathrm{C}$ (figure 12), crystallization sets in after about $25 \mathrm{~min}$; the symmetrical heat effect indicates a eutectic-type reaction. Its specific heat value corresponds to $-(75 \pm 5) \mathrm{J} \mathrm{g}^{-1}$.

After prior annealing for $1 \mathrm{~h}$ at 200 or $230^{\circ} \mathrm{C}$, the curves at $260^{\circ} \mathrm{C}$ start with endothermal effects attributable to a glass transition (broken and broken-dotted lines in figure 12); they now 


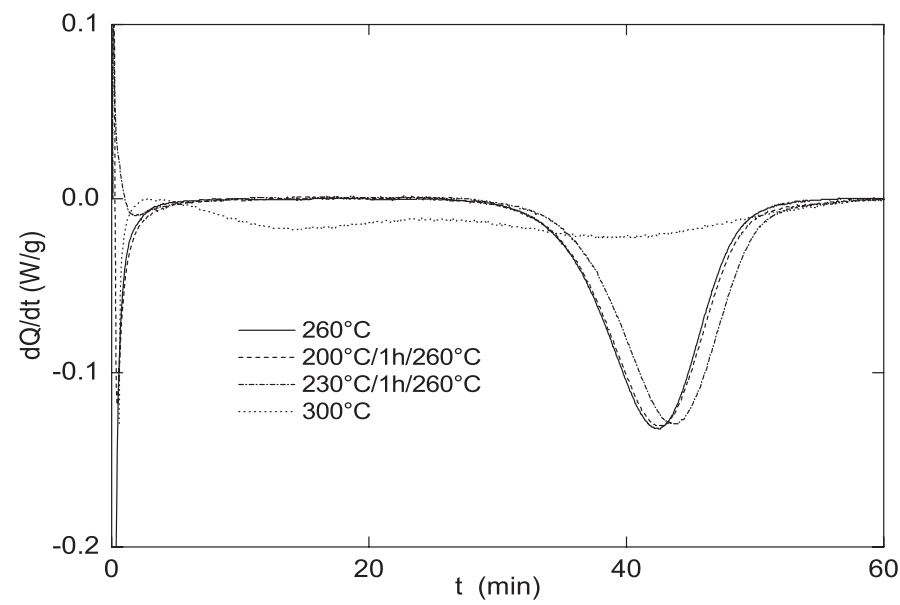

Figure 12. Heat effects accompanying the crystallization of amorphous $\mathrm{Al}_{84} \mathrm{Ce}_{6} \mathrm{Ni}_{10}\left(1400{ }^{\circ} \mathrm{C} / 44 \mathrm{~m} \mathrm{~s}^{-1}\right)$ at 260 and $300^{\circ} \mathrm{C}$ and with different preageing at $1 \mathrm{~h} / 200{ }^{\circ} \mathrm{C}$ and $1 \mathrm{~h} / 230^{\circ} \mathrm{C}$ at $260^{\circ} \mathrm{C}$.

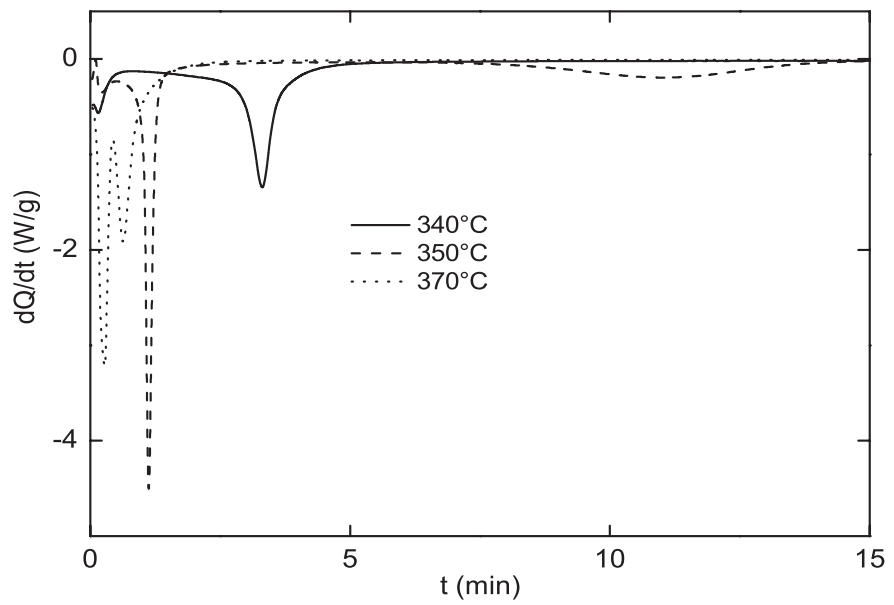

Figure 13. Heat effects accompanying the crystallization of amorphous $\mathrm{Al}_{81} \mathrm{Ce}_{10} \mathrm{Ni}_{9}\left(1300^{\circ} \mathrm{C} / 44 \mathrm{~m} \mathrm{~s}^{-1}\right)$ at 340,350 and $370{ }^{\circ} \mathrm{C}$.

show up as the overlapping exothermal effects due to relaxation and are greatly diminished. Both effects are completed before crystallization starts; the kinetics and heat value of the latter process are not changed significantly with respect to non-annealed samples. Between $300{ }^{\circ} \mathrm{C}$ (figure 12) and $325^{\circ} \mathrm{C}$, two overlapping effects amounting to $-44 \mathrm{~J} \mathrm{~g}^{-1}$ at $300^{\circ} \mathrm{C}$ accompany the transformation into the final stable phases.

Isothermal measurements of the $\mathrm{AlCe}_{10} \mathrm{Ni}_{9}$ materials were performed between 320 and $370^{\circ} \mathrm{C}$. Figure 13 shows the corrected curves recorded at $340^{\circ} \mathrm{C}$ (bold line), $350^{\circ} \mathrm{C}$ (dashed line) and $370^{\circ} \mathrm{C}$ (dotted line). At the latter temperature, the final crystalline state is attained.

3.5.2. ER isothermal investigation. With isothermal $\mathrm{ER}$ measurement the investigation of a larger time interval is possible. For the $\mathrm{Al}_{84} \mathrm{Ce}_{6} \mathrm{Ni}_{10}$ ribbons ER isothermal measurement in the temperature interval between 220 and $270^{\circ} \mathrm{C}$ and time interval between $10 \mathrm{~s}$ and $10^{6} \mathrm{~s}$ are 
(a)

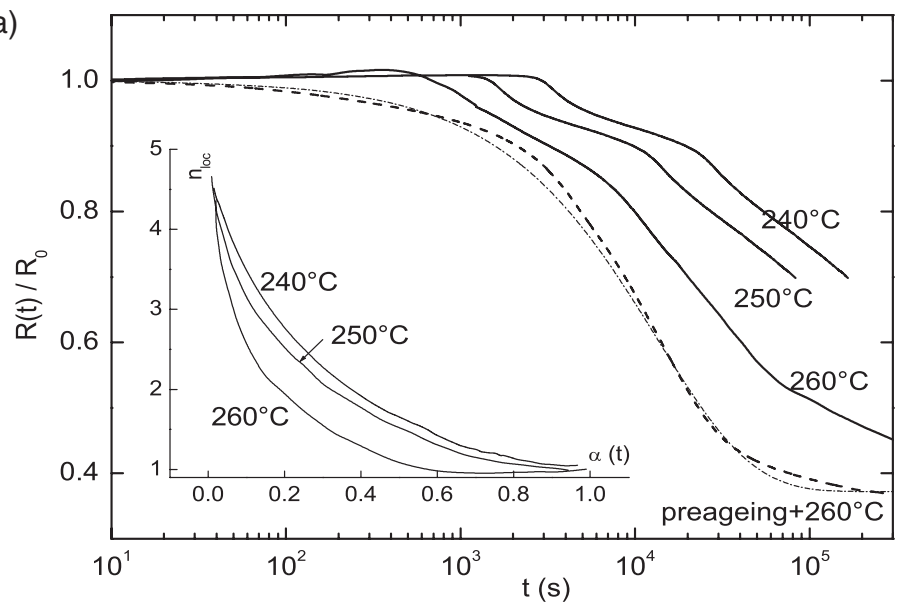

(b)

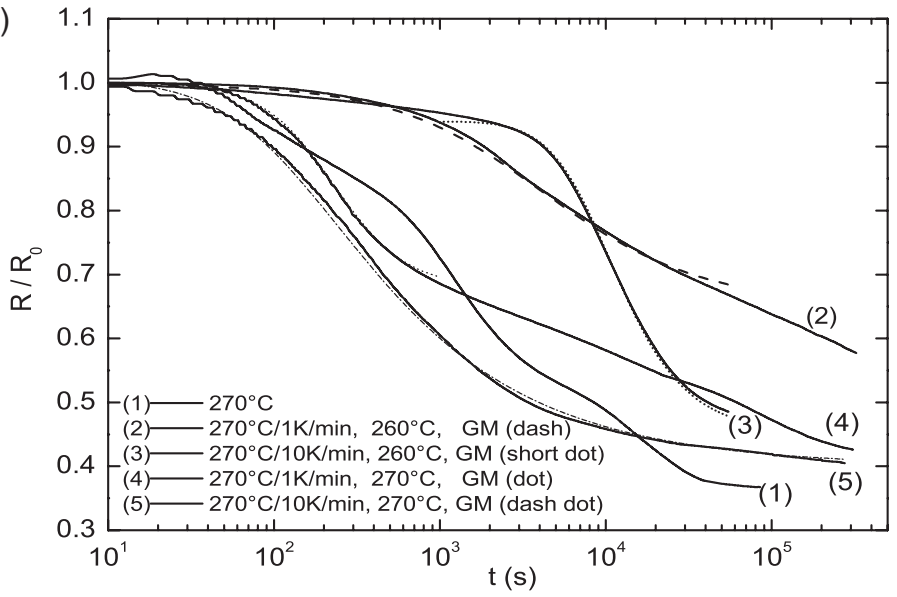

Figure 14. (a) The ER evolution during the isothermal ageing of $\mathrm{Al}_{84} \mathrm{Ce}_{6} \mathrm{Ni}_{10}\left(1300{ }^{\circ} \mathrm{C} / 44 \mathrm{~m} \mathrm{~s}^{-1}\right)$ at 240,250 and $260^{\circ} \mathrm{C}$ without preageing (full lines) and with preageing $1 \mathrm{~h} / 250^{\circ} \mathrm{C}$ (dashed line) and the model curve of the GM fit (dash-dot line); inset, the $n_{\mathrm{loc}}(\alpha)$ for the first transformation. (b) The ER evolution during the isothermal ageing of $\mathrm{AlCe}_{6} \mathrm{Ni}_{10}\left(1400^{\circ} \mathrm{C} / 44 \mathrm{~m} \mathrm{~s}^{-1}\right)$ at 260 and $270{ }^{\circ} \mathrm{C}$ after different preheatings up to $270{ }^{\circ} \mathrm{C} / 1 \mathrm{~K} / \mathrm{min}$ and $270{ }^{\circ} \mathrm{C} / 10 \mathrm{~K} / \mathrm{min}$, together with the fitted curves of the GM.

carried out for different melting conditions of the materials. In figure 14(a) the $R(t) / R_{0}$ curves for the material produced by $44 \mathrm{~m} \mathrm{~s}^{-1} / 1300^{\circ} \mathrm{C}$ are shown for $\vartheta_{\text {iso }}=240,250$ and $260{ }^{\circ} \mathrm{C}$. Three processes are visible. A modelling of the curves is only possible bit by bit.

As nucleation and growth are important factors of the crystallization processes in amorphous materials, the JMAK model [25] can be used as a starting point for the determination of the kinetic parameters $(n)$ and the activation energy $\left(E_{\mathrm{A}}\right)$ as well. But for most of the amorphous to crystalline transitions the classical JMAK equation does not exactly describe the experimental results. A first move was an enhancement of the JMAK equation by applying two kinetic parameters $\left(n_{\eta}\right.$ and $\left.\eta\right)$ in a more general JMAK model (GM). An additional parameter is used in the GM, the impingement parameter $(\eta)$ [26]. This way the difference of the transition rate of the classic JMAK can be realized. The smaller the impingement parameter $\eta$, the stronger the influence of the decrease of the ER at the beginning of the transition. The authors 
have critically and in detail discussed the different models of the determination of the kinetic parameter in early papers [27-29].

Besides the kinetic parameters $n_{\eta}$ and $\eta$, we also fitted a characteristic time $\tau_{\eta}$ depending on $\eta$ and the incubation period ( $\left.t_{\text {inc }}\right)$ in the GM. According to [27] the $n_{\eta}$ values can be expressed by $n(\alpha)$ ( $\alpha$ is the volume fraction of the transformation) [26]:

$$
n(\alpha)=\frac{\eta\left((1-\alpha)^{1 / \eta}-1\right) n_{\eta}}{\ln (1-\alpha)} .
$$

In many cases the adoption of the GM is unfortunately not enough. Therefore the determination of a local kinetic parameter $\left(n_{\text {loc }}\right)$ was introduced [28]:

$$
n_{\mathrm{loc}}(\alpha(t))=\frac{\ln (-\ln (1-\alpha(t)))}{\ln (t / \tau)} .
$$

This is the slope at each point of the Avrami plot of the JMAK model. $\tau$ is the characteristic time at $\alpha=0.63$.

The first process in the ER curves is fitted with the $n_{\text {loc }}(\alpha)$ approach (inset of figure 14(a)). The modelling with help of the local kinetic parameter $(n(\alpha))$ proved to be useful in the past, if the modelling of the ER curves with the JMAK or a more general JMAK model (GM) shows insufficient results. This is especially true for amorphous alloys.

To obtain information about the kinetics of the following crystallization process the samples are preaged differently (figures 14 (a) and (b)). The curve for $1 \mathrm{~h} / 250^{\circ} \mathrm{C}$ preageing and isothermal ageing at $260^{\circ} \mathrm{C}$ is included in figure $14(\mathrm{a})$. In figure 14 (b) the curves for the isothermal ageing at $260^{\circ} \mathrm{C}$ and $270{ }^{\circ} \mathrm{C}$ after two different continuous preheatings $(1$ and $10 \mathrm{~K} \mathrm{~min}^{-1}$ up to $270^{\circ} \mathrm{C}$ ), the influence of the preageing is demonstrated. In the case of the preheating at $1 \mathrm{~K} \mathrm{~min}^{-1}$, the beginning of the first crystallization is reached during the heating. During the heating at $10 \mathrm{~K} \mathrm{~min}^{-1}$ the region of the SL is reached and the crystallization does not begin. After heating, the samples are kept at RT for $15 \mathrm{~min}$ before the transformation at the ageing temperature $\vartheta_{\text {iso }}$ occurs within $10 \mathrm{~s}$. Several examples for these thermal regimes are shown in figure 14 (b) for the material at $44 \mathrm{~m} \mathrm{~s}^{-1} / 1400^{\circ} \mathrm{C}$. In these curves the second process can be fitted with the GM. The fit curves are included.

In figure $15(\mathrm{a})$, isothermal ER curves between 280 and $350{ }^{\circ} \mathrm{C}$ for $\mathrm{Al}_{81} \mathrm{Ce}_{10} \mathrm{Ni}_{9}$ are shown. At $280^{\circ} \mathrm{C}$ a long steady decrease of the ER takes place. At $\vartheta_{\text {iso }}=300{ }^{\circ} \mathrm{C}$ this process appears at the beginning as well, before the formation of $\mathrm{NC}$ of fcc- $\alpha-\mathrm{Al}$ is dominant. At $320^{\circ} \mathrm{C}$ ageing the formation of the $\mathrm{NC}-\mathrm{Al}$ and the formation of a $\mathrm{Al}_{4} \mathrm{Ce}$ phase is the main process. At ageing temperatures $\geqslant 340^{\circ} \mathrm{C}$ all three crystalline transformation processes are seen in the ER curves. The last process is visible as a long continuous decrease. For the fit of the kinetic parameters different models are tested; see section 4.

\section{Discussion}

The discussion will deal with structure development, the kinetic of the process and the determination of the activation energy.

- Influence of the production conditions on the as-quenched state. Although the results from the x-ray scattering are not very different for all ribbons the temperature of the melt and the cooling rate influence the atomic arrangement of the as quenched state. We define an amorphous as-quenched state as a 'frozen' image of the highly undercooled melt. The temperature range in which the undercooled melt exists, depends on both the melt temperature and the cooling rate. The cooling rate must be large enough that no significant crystalline parts are formed. There, from the beginning of the kinetic development of the ribbons, the crystal nucleation 

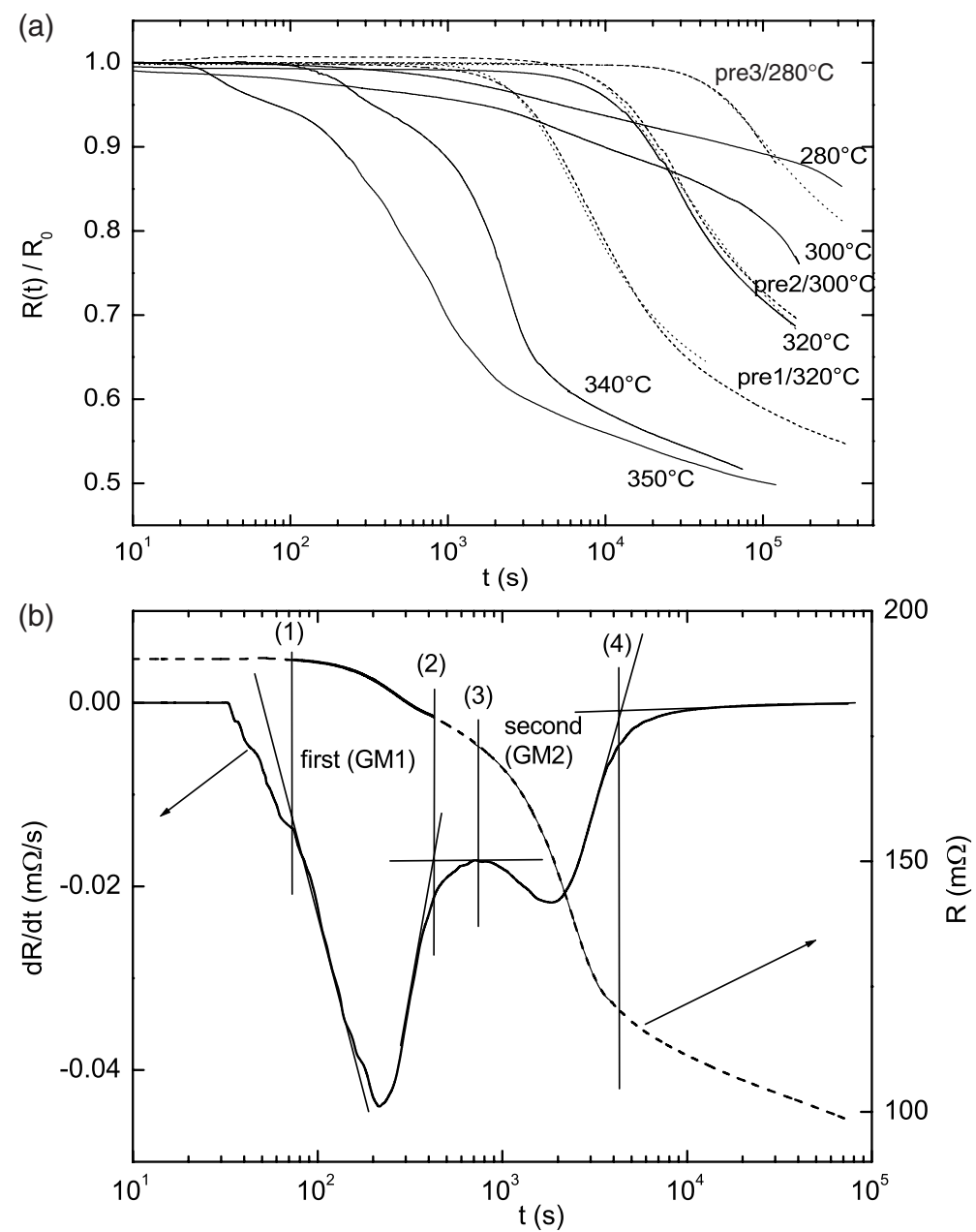

Figure 15. (a) The ER evolution during the isothermal ageing of $\mathrm{Al}_{81} \mathrm{Ce}_{10} \mathrm{Ni}_{9}\left(1300^{\circ} \mathrm{C} / 44 \mathrm{~m} \mathrm{~s}^{-1}\right)$ between $280{ }^{\circ} \mathrm{C}$ and $340^{\circ} \mathrm{C}$ without preageing and with preheating to $270{ }^{\circ} \mathrm{C} / 1 \mathrm{~K} / \mathrm{min}$ : curve pre 3 , $\vartheta_{\text {iso }}=280{ }^{\circ} \mathrm{C}$; curve pre $2, \vartheta_{\text {iso }}=300^{\circ} \mathrm{C}$; curve pre $1, \vartheta_{\text {iso }}=320^{\circ} \mathrm{C}$; dotted lines, the fit curves of the GM. (b) The derived curve $(\mathrm{d} R / \mathrm{d} t)$ (full line) of the ER curve (R) (dotted line) at $340^{\circ} \mathrm{C}$ and the fit curve of the GM1 (thick full line), intervals (1/2), and the fit curve of the GM2 (slow full line), interval (3/4).

and the growth process, nuclei can develop during the melting (worst melt conditions) if the melt passes through the nucleation region in the TTT diagram [30] or if the concentration of atoms in the near order is large enough that a nucleus can be formed. This means that in TTT diagrams the nucleation and crystallization curves are different for $\mathrm{AlCe}_{6} \mathrm{Ni}_{10}$ and $\mathrm{AlCe}_{10} \mathrm{Ni}_{9}$ during the heating. The smaller cooling passes through the nucleation and parts of the crystallization. On one hand the probability for nucleation and crystallization decreases at smaller melting temperatures; on the other hand low melting temperatures degrade the dissolution of the material during the melting time. Optimal production conditions can be determined only experimentally.

Because of the high concentration of $\mathrm{Al}$ the diffuse scattering peak stands at $38.6^{\circ}$, $Q=26.5 \mathrm{~nm}^{-1}$. The elevated shoulder for $\mathrm{AlCe}_{6} \mathrm{Ni}_{10}$ material confirms the change in 
near distance of the atoms, probably due to Al-Ni neighbour atoms. In contrast, the existence of the pre-peak in $\mathrm{AlCe}_{10} \mathrm{Ni}_{9}$ is a hint at the decomposition in form of AlCe complexes or incomplete dissolution during the melting.

- The crystallization sequence. In the $\mathrm{AlCe}_{6} \mathrm{Ni}_{10}$ materials the crystallization from the SL begins with the simultaneous formation of (fcc)- $\alpha$-Al and a second phase (similar to the eutectic crystallization), probably of a ternary metastable phase. During the SL the mobility of the atoms increases and a reordering begins. Different ternary phases are described in the literature $[22,31]$. Based on the concentration of the material the most likely is the $\mathrm{Al}_{7} \mathrm{CeNi}_{2}$ phase, crystallized in a ternary eutectic. Unfortunately, no information on the structure of this phase is published. A hexagonal AlCeNi phase [32] and a orthorhombic $\mathrm{Al}_{4} \mathrm{NiY}$ [33] have been observed. Phases of this structure could be forming during the crystallization, but the position and intensity of the diffraction pattern of our results are not consistent with this structure. The ternary phase is not thermally stable. It changes in two different phases: an early $\mathrm{Al}_{4} \mathrm{Ce}$ phase is followed by an orthorhombic $\mathrm{Al}_{3} \mathrm{Ni}$ phase. In our opinion, the $\mathrm{Al}_{4} \mathrm{Ce}$ phase has no orthorhombic structure as published in [16] but a tetragonal structure with lattice parameters $a=0.43 \mathrm{~nm}, c=1.02 \mathrm{~nm}$, space group139, $\mathrm{Al}_{4} \mathrm{Ba}-\mathrm{Typ}, I 4 / \mathrm{mmm}$ [34]. The calculated diffraction patterns of $\mathrm{Al}_{4} \mathrm{Ce}$ (tetragonal), $\mathrm{Al}$ (fcc) and $\mathrm{Al}_{3} \mathrm{Ni}$ (orthorhombic) are included in the diffraction figures (figures 8(a) and (b) and 9(a) and (b)).

Heating the melt-spun alloy at $5 \mathrm{~K} \mathrm{~min}^{-1}$ up to $570{ }^{\circ} \mathrm{C}$ assures complete crystallization. The presence of the fcc- $\alpha(\mathrm{Al})$, tetragonal- $\mathrm{Al}_{4} \mathrm{Ce}$ and orthorhombic- $\mathrm{Al}_{3} \mathrm{Ni}$ phases is confirmed by $\mathrm{XRD}$, in agreement with the precipitates observed at the Al-rich corner of the ternary equilibrium phase diagram [31]. Looking at the binary phase diagram of AlCe $[18,35]$ the eutectic point is at 4 at.\% Ce. During the rapid quenching due to the high cooling rate the materials are quenched in an extremely non-equilibrium state. At adequate melting time the melt can decompose up to a destined degree whereby concentration fluctuations form. This fluctuation concentration influences different composition in extremely small regions of the materials depending on the melting temperature. This gives the impression of eutectic crystallization. As the AlNi system is similar [18,35], the concentration of 10 at.\% Ni stabilizes this process.

Due to the non-existence of the SL the crystallization in $\mathrm{Al}_{81} \mathrm{Ce}_{10} \mathrm{Ni}_{9}$ begins with the formation of $\mathrm{NC}$ fcc $\alpha$-Al. The $\mathrm{Al}$ atoms start to form $\mathrm{NC}$ around nuclei in the amorphous matrix because of the larger mobility at the higher temperatures.

At the latter temperature, the final crystalline state is attained. In comparison to the diffraction pattern of the tetragonal- $\mathrm{Al}_{4} \mathrm{Ce}$ phase, the intensity of the fcc- $\alpha$-Al diffraction pattern is very small. This is an indication of very small and finely dispersed fcc- $\alpha$-Al crystals formed in the amorphous matrix. They are increased slowly during the heating process.

- Kinetics of the transformation. If we interpret the XRD results correctly the decomposition kinetics should be described through large $n$ values for the transformation. The modelling with the help of the JMAK model [25] was not very successful; therefore, the fit with the general model $\left(\mathrm{GM}, n_{\eta}\right)[26,27]$ and the local kinetic parameter $\left(n_{\text {loc }}\right)$ [28] is realized. The kinetic parameter $(n=a+b \cdot p)$ may be expressed as the sum of two contribution [36]. The first part $a$ is related to the nucleation rate ( 0 for no nucleation, 1 in the case of constant nucleation rate and $>1$ for irregular nucleation rate), $b$ to the dimensionality of the growth $(1,2,3)$ and $p$ the growth mechanism, which is either interface (1) or diffusion (0.5) controlled. In the classical JMAK description the kinetic parameter at $n(\alpha=0.63)$ is determined. In the case of $n_{\eta}$ and $n_{\text {loc }}$ the beginning of the transformation, the nucleation rate, is more strongly weighted.

The calorimetric isothermal investigation of $\mathrm{Al}_{84} \mathrm{Ce}_{6} \mathrm{Ni}_{10}$ ribbons, figure 12 (at $260{ }^{\circ} \mathrm{C}$ under different preageing and $300^{\circ} \mathrm{C}$ ), is more sensitive with regards to the phase 
transformation. The best fit results are $n=2.5$, a hint at the eutectic crystallization of $\mathrm{Al}_{84} \mathrm{Ce}_{6} \mathrm{Ni}_{10}$.

In the ER experiments the isothermal ageing curves are more complex. At the beginning a slight relaxation is dominant $\left(\vartheta=220-240^{\circ} \mathrm{C}\right)$. At higher temperatures $\vartheta \geqslant 240^{\circ} \mathrm{C}$ all transformation processes appear (figure 14(a)). The first process that is visible in the ER curves cannot be fitted with the GM. The fit of the local kinetic parameter $n_{\text {loc }}(\alpha)$ of the first transformation (figure 14(a) inset) yields a better fit to the experimental results. This is due to the fact that the kinetic parameters start with very high values $n>3$ and drop to $n \approx 1$ at the end. The large $n_{\text {loc }}$ values at the beginning are indicators for a large nucleation rate during the SL. Similar results were found for other materials with SL regions too [29].

The second process is fitted on the preaged materials (figure 14(b)) with the GM. Any fitting curves $(\mathrm{GM})$ are included in the figure. The $n_{\eta}$-values vary between 0.8 and 1.5 . The larger values are found for the samples with the smaller crystalline parts in the preaged state. The forming of the stable final phases can be interpreted as a growth in the long range by diffusion.

The non-existence of the $\mathrm{SL}$ in $\mathrm{AlCe}_{10} \mathrm{Ni}_{9}$ increases the mobility of the $\mathrm{Al}$ atoms during the heating so that in small regions $\mathrm{NC} \mathrm{Al}$ crystals begin to form in the residual amorphous matrix, which has as a consequence that in the residual amorphous matrix the $\mathrm{Ce}$ and $\mathrm{Ni}$ contents increase relatively. The crystallization of the residual amorphous matrix is difficult to understand. In the DSC scan only one exothermal transformation is visible after the strong crystallization peak (figure 2(b)). In our opinion no ternary phase forms, but instead a supersaturated eutectic of two phases, $\mathrm{Al}_{4} \mathrm{Ce}$ and $\mathrm{Al}_{3} \mathrm{Ni}$. The $\mathrm{Al}_{3} \mathrm{Ni}$ is so finely dispersed that it cannot be identified in the $\mathrm{x}$-ray diffraction pictures at the beginning. It can only be identified during its growth at higher temperatures. The last exothermal peak describes the transformation of the metastable $\mathrm{Al}_{4} \mathrm{Ce}$ phase in the tetragonal structure, similar to the $\mathrm{Al}_{84} \mathrm{Ce}_{6} \mathrm{Ni}_{10}$ material.

The isothermal ER curves show a strong relaxation only at temperatures $\vartheta \leqslant 270^{\circ} \mathrm{C}$. At $\vartheta=280$ and $300^{\circ} \mathrm{C}$ (figure 15 (a)) a long slow decrease of the ER is observed and crystallization begins above $t>10^{5} \mathrm{~s}$. A GM fit of this decay gives an $n_{\eta}$-value of about one with very large $\eta$-values. This result indicates a strong relaxation process with the result of a decomposition of the amorphous matrix. The following crystallization $\left(\vartheta_{\text {iso }}=320^{\circ} \mathrm{C}\right)$, the formation of the fcc- $\alpha$-Al, yields $n_{\eta}$-values of about 2 with the GM, typical for primary crystallization. The formation of the $\mathrm{Al}_{4} \mathrm{Ce}$ phase cannot be isolated in this curve. All three processes are visible at $\vartheta_{\text {iso }} \geqslant 340^{\circ} \mathrm{C}$. These curves are fitted in the following way. The first and second part is fitted separately with the GM. The beginning and the end of these two parts were determined from the derived ER $(\mathrm{d} R / \mathrm{d} t)$ curves with the tangent method (figure 15(b)), while we apply lines to the inflection points of the derived ER curves. The intersection points of two adjacent lines are the initial point ((1) for the GM1 and (3) for GM2) and the end point ((2) for GM1 and (4) for GM2) of the fit interval. The fit of the first range (GM1), the formation of the fcc- $\alpha$-Al, gives $n_{\eta}$-values between 3 and 3.5. The second range (GM2) yields $n_{\eta}$-values of about 2.5. The different kinetic parameters for the same process at different temperatures can be explained for the different state at the beginning of the crystallization. If the materials have enough time for relaxation $\left(\vartheta_{\text {iso }} \leqslant 300^{\circ} \mathrm{C}\right)$ they can form nuclei that can grow to the critical size for crystallization. From the crystalline structure the growth is visible. In the case of larger temperatures $\left(\vartheta_{\text {iso }} \geqslant 340^{\circ} \mathrm{C}\right)$ nucleation and growth occur together, so that from the beginning larger kinetic parameters are present. The transformation starts with a large value for the first process $n_{\eta}=3-3.5$. This corresponds to long range diffusion in the residual amorphous matrix. For the following process a kinetic parameter of $n_{\eta}=2.3$ is fitted. This result is only understandable if it is accepted that there is not enough time for nucleation during the transformation from RT to $\vartheta_{\text {iso }}$. 
To test this result the isothermal ageing is measured after different preageings. Materials are preaged with 1 or $10 \mathrm{~K} \mathrm{~min}^{-1}$ up to $270{ }^{\circ} \mathrm{C}$ (figure 6(e)) hold at RT $15 \mathrm{~min}$ and then isothermally aged at $280^{\circ} \mathrm{C}$ up to $340^{\circ} \mathrm{C}$. Isothermal ageing curves together with the fit curves of the GM are included in figure 15(a). The kinetic parameter changes from $n_{\eta}=2.4$ (preageing $1 \mathrm{~K} \mathrm{~min}^{-1}, \vartheta_{\text {iso }}=280{ }^{\circ} \mathrm{C}$, curve pre3) to $n_{\eta} \approx 2$ (preageing $1 \mathrm{~K} \mathrm{~min}^{-1}$, $\vartheta_{\text {iso }}=300^{\circ} \mathrm{C}$, curve pre2) up to $n_{\eta} \approx 1.5$ for the first and the second crystalline process at preageing $1 \mathrm{~K} \mathrm{~min}^{-1}$ and isothermal ageing at $320^{\circ} \mathrm{C}$ (curve pre1). During the preageing nucleation takes place in different ways, depending on the heating rate. The crystallization continues more or less intensively during the isothermal ageing. These results affect the determination of the activation energy.

- The activation energy. The mean activation energy $E$ can be determined in two ways, the Kissinger method [37] and the Arrhenius equation (31). The Kissinger method applies for experiments with constant heating rates $T_{H}=\mathrm{d} T / \mathrm{d} t$ :

$$
\ln \left(T_{\alpha}^{2} / T_{H}\right)=E_{Q} /\left(k_{\mathrm{B}} \cdot T_{\alpha}\right)+\text { const. }
$$

In DSC experiments $T_{\alpha}$ is the temperature in the heat flow extremum.

The Arrhenius equation starts from isothermal measurements:

$$
K_{T}=k_{0} \exp \left(-E_{\mathrm{A}} /\left(k_{\mathrm{B}} \cdot T\right)\right) .
$$

The application of the JMAK model yields the condition that $K_{T}=\tau^{-1}$. This corresponds to the ageing time at $\alpha(\tau)=1-e^{-1}=0.63$. The slope in a plot of $\ln (\tau)=f\left(T_{\text {iso }}^{-1}\right)$ is proportional to the activation energy. Modelling with the JMAK equation, that means $n(\alpha)=$ const, is often not possible. Therefore, we have to be cautious when using equations (4) and (5).

The activation energies of $\mathrm{AlCe}_{6} \mathrm{Ni}_{10}$ material $\left(130{ }^{\circ} \mathrm{C} / 44 \mathrm{~m} \mathrm{~s}^{-1}\right)$ determined by the Kissinger method for four different heating rates $\left(1,2,5,20 \mathrm{~K} \mathrm{~min}^{-1}\right)$ are equal to $(4.3 \pm 0.2) \mathrm{eV}$ for the eutectic crystallization and $(1.7 \pm 0.2)$ and $(2.2 \pm 0.1) \mathrm{eV}$ for the last two transitions. Attempting to determine the activation energy of the SL with the glass transition temperature (GT) yields very high values $(6.6 \pm 0.4) \mathrm{eV}$.

The $E_{\mathrm{A}}$-values are deduced from the time shift (neglecting incubation time) of the heat flow minima of the isothermal ageing curves: $(4.16 \pm 0.11) \mathrm{eV}$ for the eutectic crystallization; $(1.68 \pm 0.05)$ and $(2.11 \pm 0.06) \mathrm{eV}$ for the two final transitions. These values are in excellent agreement with those deduced from the continuous heating experiments.

The activation energy determined from the isothermal ER curves in the temperature interval of $230-260{ }^{\circ} \mathrm{C}$ of the first transition is fitted with $E_{\mathrm{A}}=(2.9 \pm 0.1) \mathrm{eV}$.

The authors in $[38,39]$ differ between the activation energy for nucleation, for growth of the particles and the total process. The high values of the calorimetric measurements (constant heating and isothermal ageing at quite large temperatures) give the activation energy of the total process. At lower temperatures in the case of the ER measurements there is enough time for the formation of a nucleus that is followed by crystallization.

In the case of the $\mathrm{Al}_{81} \mathrm{Ce}_{10} \mathrm{Ni}_{9}$ materials $\left(1300^{\circ} \mathrm{C} / 44 \mathrm{~m} \mathrm{~s}^{-1}\right)$ the measurement points for the analysis with the Kissinger method show deviations from the linearity. Such a deviation is very rare in DSC investigation. The authors in [40] have published results about deviations from linearity of the Kissinger method too.

A linear fit with the values of all heating rates from 1 up to $20 \mathrm{~K} \mathrm{~min}^{-1}$ appears therefore not sensible. The fitting with the values of the small heating rates $\left(1,2,5 \mathrm{~K} \mathrm{~min}^{-1}\right)$ with a good linearity only gives $(3.2 \pm 0.2) \mathrm{eV}$. Looking at the DSC curves, the formation of the NC is more visible for smaller heating rate. This has an effect on the activation of the crystallization of the residual amorphous matrix. The fit of the isothermal ageing curves in the temperature interval from $330^{\circ} \mathrm{C}$ up to $360^{\circ} \mathrm{C}$ gives $(3.3 \pm 0.1) \mathrm{eV}$ for the first peak. The second peak in the DSC curve drifts further from linearity. For small heating rates the activation energy is 
$(1.85 \pm 0.05) \mathrm{eV}$, for large heating rates $\geqslant 3.8 \mathrm{eV}$, depending on the interval. The calorimetric isothermal measurement fitting with the Arrhenius equation in the temperature interval (340$\left.370^{\circ} \mathrm{C}\right)$ gives different activation energies too. The activation energy is fitted to $(3.5 \pm 0.1) \mathrm{eV}$ in the interval $340-350^{\circ} \mathrm{C}$. The value is in good coincidence with the value for the small heating rates. For the interval $350-370^{\circ} \mathrm{C}$ the activation energy is fitted to $E_{\mathrm{A}}=(4.5 \pm 0.2) \mathrm{eV}$. This means that the larger the isothermal temperature, the bigger the activation energy. For larger heating rates and larger ageing temperatures nucleation and growth are superposed.

From ER measurement the fit of the activation energy is done for the forming of the NC fcc- $\alpha-\mathrm{Al}$ in the temperature interval from 280 to $330^{\circ} \mathrm{C}$ with $E_{\mathrm{A}}=(4.1 \pm 0.3) \mathrm{eV}$. The activation energy of the second transition (the formation of the $\mathrm{Al}_{4} \mathrm{Ce}$ phase in the $\mathrm{ER}$ curves of the preaged materials $\left.\left(1 \mathrm{~K} \mathrm{~min}^{-1} / 280{ }^{\circ} \mathrm{C}\right)\right)$ is $(2.4 \pm 0.1) \mathrm{eV}$.

The activation energy for the transition from the amorphous to the first crystalline structure expresses the stability of the amorphous state. Large activation energies have been determined for other ternary Al-rich amorphous materials (an overview for AlLnT is given in [41]). An additional comparison yields that the activation energy correlates with the crystallization temperature. The essential higher crystallization temperatures for the $\mathrm{Al}-\mathrm{Ce}-\mathrm{Ni}$ amorphous alloys investigated in this work and the relatively large values of the activation energies for the amorphous to the crystalline transition are an expression of this large stability of the amorphous structure of Al-Ce-Ni materials.

\section{Conclusion}

$\mathrm{Al}_{84} \mathrm{Ce}_{6} \mathrm{Ni}_{10}$ and $\mathrm{Al}_{81} \mathrm{Ce}_{10} \mathrm{Ni}_{9}$ amorphous materials produced at different melting and cooling conditions adapt to the known concept of the Al-Ce-Ni alloys. It was confirmed that the material $\mathrm{Al}_{84} \mathrm{Ce}_{6} \mathrm{Ni}_{10}$ transforms from the amorphous state by $\mathrm{SL}$, while the $\mathrm{Al}_{81} \mathrm{Ce}_{10} \mathrm{Ni}_{9}$ material forms NC fcc- $\alpha$-Al. Detailed investigation of the sequence for both materials yields that the crystallization is different from published results. From a ternary eutectic in the case of $\mathrm{Al}_{84} \mathrm{Ce}_{6} \mathrm{Ni}_{10}$ a tetragonal $\mathrm{Al}_{4} \mathrm{Ce}$ forms and not an orthorhombic phase. It is confirmed that the large concentration of Ni stabilizes the amorphous state. The larger concentration of Ce shifts the crystallization temperature in the $\mathrm{Al}_{81} \mathrm{Ce}_{10} \mathrm{Ni}_{9}$ material to higher values. It also influences the stability of the production of the amorphous materials. Insufficient cooling rates and melting temperatures increase crystalline parts in the as-quenched state.

The materials show that the dynamic of the crystallization process strongly depends on the amorphous state, the expansion of the relaxation or the SL. Preageing influences the stability of the amorphous state and the crystallization process more strongly than the melting and quenching conditions of the liquid. This influence can be gained in the run of the kinetic parameter and the activation energy for the different transformation. The $\mathrm{Al}_{81} \mathrm{Ce}_{10} \mathrm{Ni}_{9}$ reacts more sensitively on the parameter than the $\mathrm{Al}_{84} \mathrm{Ce}_{6} \mathrm{Ni}_{10}$ material.

\section{Acknowledgments}

One of the authors (US) thanks Ch Y Zahra for the careful calorimetric measurements and Dr A-M Zahra for the helpful discussion of the calorimetric dates.

\section{References}

[1] Inoue A, Ohtera K, Tsai A P, Kimura H and Masumoto T 1988 Japan. J. Appl. Phys. 27 L1579

[2] Inoue A, Ohtera K, Kita K and Masumoto T 1988 Japan. J. Appl. Phys. 27 L1796 
[3] Nakazato K, Kawamura Y, Tsain A P, Inoue A and Masumoto T 1993 Appl. Phys. Lett. 632644

[4] Matsuura M, Sakurai M, Kim S H, Tsai A P, Inoue A and Suzuki K 1996 Mater. Sci. Eng. A 217/218 397

[5] Inoue A 1997 Handbook on the Physics and Chemistry of Rare Earths vol 24, ed K A Gschneider Jr and L Eyring (Amsterdam: Elsevier Science B.V.) p 83

[6] Tsai A P, Kamiyama T, Kawamura Y, Inoue A and Masumoto T 1997 Acta Mater. 451477

[7] Munoz-Morris M A, Surinach S, Varga L K, Baro M D and Morris D G 2002 Scr. Mater. 4731

[8] Zh F, Wu Y S, Shi Y C, Xu A H, Zhu Z Q and Zh G R 2002 J. Phys.: Condens. Matter 147949

[9] Zh F, Wu Y S, Shi Y C, Zh C J and Zhu Z Q 2003 Mater. Sci. Eng. A 340212

[10] Zh F, Wu Y S, Zh C J, Zhu Z Q, Shi Y C and Zh G R 2002 J. Phys.: Condens. Matter 141163

[11] Zh F, Wu Y S, Shi Y C, Zh G R and Xu A H 2003 Trans. Nonferrous Met. Soc. China 1388

[12] Manov V, Rubshtein A, Voronel A, Popel P and Vereshagin A 1994 Mater. Sci. Eng. 179/180 91

[13] Cochrane R F, Schumacher P and Greer A L 1991 Mater. Sci. Eng. A 133367

[14] Schmidt U, Eisenschmidt C, Vieweger T, Zahra C Y and Zahra A-M 2000 J. Non-Cryst. Solids 27129

[15] Fleming M C 1991 Solidification Processing in Materials Science and Technology vol 15, ed R W Cahn, P Haasen and E J Kramer (New York: VCH) p 2

[16] JCPDS 19-0006 1997

[17] Faber T E and Ziman J M 1965 Phil. Mag. 11153

[18] Masalsky T B (ed) 1990 Binary Alloy Phase Diagrams 2nd edn (Metals Park, OH: ASM International)

[19] Zahra A-M, Menguy N, Charai A and Schmidt U 2000 J. Etude Equilibres entre Phases 26231

[20] Hono K, Zhang Y, Inoue A and Sakurai T 1995 Mater. Trans., JIM 36909

[21] Schröder K 1983 CRC Handbook of Electrical Resistivities of Binary Metallic Alloys (Boca Raton, FL: CRC Press)

[22] Villars P, Prince A and Okamoto H (ed) 1995 Handbook of Ternary Alloy Phase Diagrams vol 3 (Metals Park, $\mathrm{OH}$ : ASM International)

[23] JCPDS 02-0416Q 1997

[24] Kim S G, Inoue A and Masumoto T 1990 Mater. Trans. JIM 74731

[25] Chistian J W 1975 The Theory of Transformation in Metals and Alloys part I (Oxford: Pergamon)

[26] Starink M J and Zahra A-M 1997 Thermochim. Acta 292159

[27] Schmidt U, Schmidt B, Zahra C Y and Zahra A-M 1999 Proc. Int. Conf. on Light Alloys and Composites (Zakopane) p 91

[28] Schmidt U and Schmidt B 2000 J. Mater. Sci. Lett. 192183

[29] Schmidt U and Schmidt B 2002 J. Non-Cryst. Solids 31161

[30] Perepezko J H, Hebert R J, Wu R I and Wilde G 2003 J. Non-Cryst. Solids 31752

[31] Borzone G, Parodi N, Raggio R and Ferro R 1999 J. Etude Equilibres entre Phases 2525

[32] JCPDS 21-0752Q 2001

[33] JCPDS 50-1236Q 2001

[34] JCPDS 10-0250Q 2001

[35] Predel B 1991 Phase Equilibria, Crystallographic and Thermodynamic Data of Binary Alloys Ac-Au ...Au-Zr Landolt-Börnstein, New Series IV/5a ed O Madelung (Berlin: Springer) p 150

[36] Cumbrera F L and Sanchez-Bajo F 1995 Thermochim. Acta 266315

[37] Kissinger H E 1957 Anal. Chem. 291702

[38] Ranganathan S and von Heimdahl M 1981 J. Mater. Sci. 162401

[39] Ranganathan S and Suryanarayana C 1985 Mater. Sci. Forum 3173

[40] Battezzati L, Pozzovivo S and Rizzi P 2002 Mater. Trans. 432593

[41] Schmidt U and Zahra A-M 2002 Recent Res. Dev. Mater. Sci. 3401 